\title{
Phosphorylation in the Charged Linker Modulates Interactions and Secretion of Hsp90 $\beta$
}

\author{
Lorenz Weidenauer and Manfredo Quadroni *
}

check for

updates

Citation: Weidenauer, L.; Quadroni, M. Phosphorylation in the Charged Linker Modulates Interactions and Secretion of Hsp90 $\beta$. Cells 2021, 10, 1701. https://doi.org/10.3390/ 10.3390/cells10071701

Academic Editor: Alexander E. Kabakov

Received: 18 May 2021

Accepted: 30 June 2021

Published: 5 July 2021

Publisher's Note: MDPI stays neutral with regard to jurisdictional claims in published maps and institutional affiliations.
Protein Analysis Facility, Faculty of Biology and Medicine, University of Lausanne, 1015 Lausanne, Switzerland; lorenz.weidenauer@unil.ch

* Correspondence: manfredo.quadroni@unil.ch

\begin{abstract}
Hsp90 $\beta$ is a major chaperone involved in numerous cellular processes. Hundreds of client proteins depend on Hsp90 $\beta$ for proper folding and/or activity. Regulation of Hsp $90 \beta$ is critical to coordinate its tasks and is mediated by several post-translational modifications. Here, we focus on two phosphorylation sites located in the charged linker region of human Hsp90 $\beta$, Ser226 and Ser255, which have been frequently reported but whose function remains unclear. Targeted measurements by mass spectrometry indicated that intracellular Hsp90 $\beta$ is highly phosphorylated on both sites (>90\%). The level of phosphorylation was unaffected by various stresses (e.g., heat shock, inhibition with drugs) that impact Hsp90 $\beta$ activity. Mutating the two serines to alanines increased the amount of proteins interacting with Hsp90 $\beta$ globally and increased the sensitivity to tryptic cleavage in the C-terminal domain. Further investigation revealed that phosphorylation on Ser255 and to a lesser extent on Ser226 is decreased in the conditioned medium of cultured K562 cells, and that a nonphosphorylatable double alanine mutant was secreted more efficiently than the wild type. Overall, our results show that phosphorylation events in the charged linker regulate both the interactions of Hsp90 $\beta$ and its secretion, through changes in the conformation of the chaperone.
\end{abstract}

Keywords: heat shock protein 90; chaperone; charged linker; phosphorylation; interactome; proteomics

\section{Introduction}

Heat shock protein 90 (Hsp90) is an important family of highly conserved chaperones responsible for the proper folding, the stabilization, and the targeting for degradation of many proteins [1-4]. It is involved in numerous cellular processes and Hsp90 regulation is critical to coordinate its activity. The increasing complexity of Hsp90's environment during evolution required additional cellular strategies to accommodate and regulate Hsp90 chaperone function [5].

There are two Hsp90 isoforms in the human cytosol, Hsp90 $\alpha$ and Hsp90 [6,7]. The $\beta$ isoform is considered to be the constitutively expressed isoform, while the $\alpha$ isoform is considered to be the stress inducible one, for example upon heat shock. Regulation of Hsp90 chaperone function is mediated through protein-protein interactions and post-translational modifications (PTMs) [8-11]. A set of proteins assisting Hsp90, the co-chaperones, allow for the fine-tuning of Hsp90 chaperoning activity and its interactions with the substrate proteins, usually referred to as the clients [12]. A complex set of PTMs is known to occur on Hsp90 which, together, concur to modulate its interactions and activity, resulting in a "chaperone code" analog to the one known for histones [13].

The Hsp90 protein is composed of three main domains: an N-terminal (N) domain with an ATP binding pocket and ATPase activity, a middle (M) domain, mostly involved in binding co-chaperones and clients, and a C-terminal (C) domain which mediates dimerization and possesses a EEVD motif involved in the binding of tetratricopeptide repeat domains. The charged linker (CL), absent in bacteria but present in eukaryotes, is a very 
peculiar stretch of charged residues connecting the $\mathrm{N}$ and $\mathrm{M}$ domains [14]. The $\mathrm{CL}$ influences $\mathrm{N}$ versus $\mathrm{M}$ domain conformational rearrangements, regulates affinity for ATP, ATPase activity, protein-protein interactions, extracellular secretion and Hsp90 function in general [15-26]. Even if it has been shown to be dispensable for viability in yeast, a minimal linker length is assumed to be necessary for optimal Hsp90 function $[17,19,27,28]$. By comparison, the E. coli ortholog HtpG, which lacks the CL, has a much more compact structure with little interdomain flexibility. In HtpG, the region spanning the CL insertion folds as an antiparallel $\beta$-sheet, with the $C L$ insertion located between $\beta$-strands 8 and 9 [29].

The structure of eukaryotic CL remains elusive since the linker is mostly not resolved on crystal structures and is thought to be highly exposed to solvent. An early study suggested that the CL in chicken Hsp90 forms two $\alpha$-helices separated by a prolinecontaining loop [30]. A study partly supported this finding: in yeast Hsp90, two regions with residual secondary structure (RSS) separated by a proline containing loop were detected [31]. The region with RSS at the C-terminal side of the loop, which includes the corresponding $\beta$-strand 9 in $\mathrm{HtpG}$, can interact with and increase the exposure of $\beta$-strand 8 , which serves as a contact site for some Hsp90 clients such as p53. The CL is also able to dock onto the $\mathrm{N}$ domain and decrease its rotational freedom [20].

Specific features in the CL sequence are known to regulate Hsp90 function and global conformation, but the exact residues exerting these effects have not been determined $[19,20,31]$. The CL in yeast contains four prolines, but only one is conserved in chicken and humans, in the flexible middle loop. Conversely, three serines are present in the human sequence, while none are found in yeast. While sequence alignments are difficult due to the different length of the CL, it is clear that P218 in yeast is replaced by S226 in chicken and human Hsp90 $\beta$. Two other serines are present in the CL of human Hsp90 $\beta$, S255 and S261, within the region interacting with $\beta$-strand 8.

Early evidence suggested that 226 and S255 in Hsp90 $\beta$ and the corresponding S231 and S261 in Hsp90 $\alpha$ are constitutively phosphorylated in humans [32]. Similarly, Hsp90 was identified as early as 1982 as a major cellular phosphoprotein in chicken liver and embryo fibroblasts [33,34]. Reports on rat and pig Hsp90 are in line with this view $[35,36]$.

The sequences surrounding S226 and S255 present a typical casein kinase II (CK2) substrate motif and indeed CK2 can phosphorylate the CL of cytosolic Hsp90 $\beta$ in vitro [32]. Studies using CK2 knock-out cell lines and inhibitors have however questioned CK2 as the sole kinase responsible for these PTMs in vivo [37,38]. It has been reported that cells expressing leukemogenic tyrosine kinases (such as Bcr-Abl expressing K562 cells) have lower phosphorylation of the CL but the evidence is mixed [39-41].

So far, a general mechanism of regulation for CL phosphorylation has not been described. Large scale phosphoproteomics studies typically highlight S226 and S255 as quantitatively prominent phosphorylated sites (www.phosphosite.org, accessed on 17 May 2021) but do not provide a coherent regulation model. Interestingly, early studies suggested that the phosphorylation turnover of Hsp90 is slow in HeLa cells under normal conditions, but more rapid during heat shock [32,42]. One of the most recent result is the observation that the phosphorylation of S255 in Hsp90 $\beta$ in tissues derived from patients with cholangiocarcinoma (CCA) varies between tumor stages [43].

Phosphorylation of S226 and S255 was reported to regulate a few protein-protein interactions [39,44,45]. Unphosphorylated Hsp90 has increased binding to Apaf-1 and AhR, whereas phosphorylated Hsp90 can interact with PXR. CK2 phosphorylation on S226 and S255 in Hsp90 $\beta$ and on S13 in CDC37 was suggested to destabilize the Hsp90-CDC37 complex in presence of ADP [46]. Finally, in $\mathrm{Hsp} 90 \alpha$, mutating the homologous residues S231 and S263 to alanines reduced the activity of the client hTERT [47].

Considering the reported importance of the CL for Hsp90 $\beta$ chaperone activity, we speculated that S226 and S255 phosphorylation impacts more protein-protein interactions and maybe more functions than those already reported in the literature. 
We thus set up a method using liquid chromatography coupled to tandem mass spectrometry (LC-MS/MS) to determine the phosphorylation occupancy (the percentage of phosphorylated residues) of S226 and S255 in Hsp90 $\beta$ in several human cell lines, and investigate with proteomic tools if their mutation to alanines impacts protein-protein interactions with Hsp90 $\beta$. We also investigated if the mutations alter Hsp90 $\beta$ binding to ATP / ADP or its global conformation. Furthermore, we searched for conditions that regulate S226 and S255 phosphorylation to provide clues on possible biological function of these post-translational modifications.

\section{Materials and Methods}

\subsection{Plasmids}

Plasmids were generated using standard procedures and verified by sequencing. pCMV3-HA-Hsp90 $\beta^{\text {WT }}$ ("WT plasmid") was ordered from SinoBiological Inc. (Beijing, China; HG11381-NY), which served as template to produce pCMV3-Hsp90 $\beta^{\text {S226A/S255A }}$ ("AA plasmid") and no tag control plasmids.

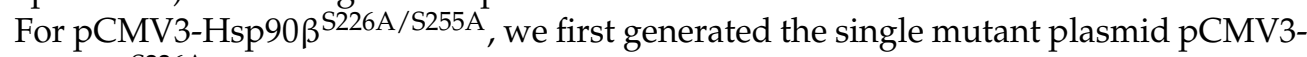
HA-Hsp90 $\beta^{\text {S226A }}$ by (1) using primers A1 and A2 (see Table 1) to amplify the C-terminal DNA fragment with the S226A mutation, (2) using primers A3 and A4 to amplify the Nterminal DNA fragment with the S226A mutation, (3) doing an overlap extension PCR with the fragments obtained in (1) and (2) to produce the entire Hsp $90 \beta^{\text {S226A }}$ DNA fragment, and finally (4) inserting the final product back into the original plasmid. We then used the primer pairs A2/A5 and A3/A6 to introduce the S255A mutation in the same way to obtain the double mutant plasmid pCMV3-HA-Hsp90 $3 \beta^{\text {S226A/S255A }}$.

Table 1. List of primers used to generate Hsp90 mutants.

\begin{tabular}{cc}
\hline Primer Name & Primer Sequence $\mathbf{( 5}^{\prime} \mathbf{-} \mathbf{3}^{\prime} \mathbf{)}$ \\
\hline A1 & AAGGAAATTGCTGATGATGAGGCAG \\
A2 (BGH_Reverse) & TAGAAGGCACAGTCGAGG \\
A3 (T7_forward) & TAATACGACTCACTATAGGG \\
A4 & CATCATCAGCAATTTCCTTCTCTCG \\
A5 & ATGTGGGTGCAGATGAGGAGG \\
A6 & TCATCTGCACCCACATCTTCG \\
\hline
\end{tabular}

For pCMV3-Hsp90 $\beta^{\mathrm{WT}}$ (no tag control), we generated a KpnI-ATG-Hsp90 $\beta^{\mathrm{WT}} \mathrm{N}$ terminal DNA fragment with primers A7 and A4 (the point mutation is removed upon digestion of the fragment for insertion) to replace the N-terminal sequence with the HA-tag in the original plasmid.

\subsection{Mammalian Cell Culture}

HEK293T-Hsp90ßKO19 cells from Didier Picard's lab were grown in DMEM (Thermo Fischer Scientific, San Jose, CA, USA; 41966-029) supplemented with 10\% (v/v) FBS (Pan Biotech, Aidenbach, Germany; P40-37500), 100 units /mL penicillin and $100 \mu \mathrm{g} / \mathrm{mL}$ streptomycin (Thermo Fischer Scientific 15140-122), at $37^{\circ} \mathrm{C}$ under $5 \%(v / v) \mathrm{CO}_{2}$ [48].

For Stable Isotope Labeling with Amino acids in Cell culture (SILAC), HEK293THsp90ßKO19 cells were labeled with light and heavy isotopes of lysine and arginine [49]. Base growth medium was prepared with DMEM for SILAC (Thermo Fischer Scientific; 88364) supplemented with 10\% (v/v) dialyzed FBS (Merck, Darmstadt, Germany; F0392), 100 units $/ \mathrm{mL}$ penicillin and $100 \mu \mathrm{g} / \mathrm{mL}$ streptomycin. Lysine and arginine isotopes were added as follows: $150 \mathrm{mg} / \mathrm{L}^{12} \mathrm{C}_{6}{ }^{14} \mathrm{~N}_{2}$-L-lysine (Merck; L5751) and $50 \mathrm{mg} / \mathrm{L}^{12} \mathrm{C}_{6}{ }^{14} \mathrm{~N}_{4^{-}}$ L-arginine (Merck; A6969) to light medium, $150 \mathrm{mg} / \mathrm{L}^{13} \mathrm{C}_{6}{ }^{15} \mathrm{~N}_{2}$-L-lysine (Cambridge Isotope Laboratories Inc., Tewksbury, MA, USA; CNLM-291-H-0.1) and $50 \mathrm{mg} / \mathrm{L}^{13} \mathrm{C}_{6}{ }^{15} \mathrm{~N}_{4}{ }^{-}$ L-arginine (Cambridge Isotope Laboratories Inc.; CNLM-539-H-0.1) to heavy medium. $200 \mathrm{mg} / \mathrm{L}$ unlabeled proline (Merck; P5607) was added as excess in all SILAC media to 
limit the arginine to proline metabolic conversion. A labeling efficiency greater than $95 \%$ was confirmed by mass spectrometry.

For occupancy experiments, AsPC-1 (ATCC, Manassas, VA, USA; CRL-1682) and MDA-MB-468 (ATCC; HTB-132) cells were grown in DMEM/F12 medium (Thermo Fischer Scientific; 31331-028). OCI-Ly1 (DSMZ, Braunschweig, Germany; ACC 722) cells were grown in IMDM medium (Thermo Fischer Scientific; 12440-053). K562 cells (ECACC Public Health England, Salisbury, UK; 89121407) were grown in RPMI1640 medium (Thermo Fischer Scientific; 61870-010). HMEC (ATCC; PCS-600-010) cells were grown in HMEC medium (ATCC; PCS-600-030) supplemented with HMEC growth kit (ATCC; PCS-600040). All media except for HMEC were supplemented with 10\% (v/v) FBS, 100 units/mL penicillin and $100 \mu \mathrm{g} / \mathrm{mL}$ streptomycin. All cells were grown at $37^{\circ} \mathrm{C}$ in a humidified incubator under $5 \%(v / v) \mathrm{CO}_{2}$. For the heavy labeled reference cells, $\mathrm{K} 562$ cells were grown in RPMI160 for SILAC (Thermo Fischer Scientific; 88365) supplemented with 10\% $(v / v)$ dialyzed FBS, 100 units $/ \mathrm{mL}$ penicillin, $100 \mu \mathrm{g} / \mathrm{mL}$ streptomycin, $100 \mathrm{mg} / \mathrm{L}^{13} \mathrm{C}_{6}{ }^{15} \mathrm{~N}_{2}$ - Llysine, $100 \mathrm{mg} / \mathrm{L}^{13} \mathrm{C}_{6}{ }^{15} \mathrm{~N}_{4}$-L-arginine, and $180 \mathrm{mg} / \mathrm{L}$ unlabeled proline. Cells were frozen as $30-50 \mu \mathrm{L}$ pellets when they reached near maximal confluence or density $(80 \%$ confluence for adherent cells and 0.8 million $/ \mathrm{mL}$ density for suspension cultures) right after two washes with $15 \mathrm{~mL}$ cold PBS. Cells were not tested for mycoplasma contamination before experiments.

\subsection{Cell Transfection}

HEK293T-Hsp90ßKO19 cells were transfected using the calcium phosphate method [50]. Plasmids were added to one volume of $250 \mathrm{mM} \mathrm{CaCl}_{2}$ (Merck; 21097), the solution was then added drop by drop to another volume of HBS $2 \times$ buffer (50 mM HEPES (Merck; H4034), $280 \mathrm{mM} \mathrm{NaCl}$ (Merck 1.06404, $1.5 \mathrm{mM} \mathrm{Na}_{2} \mathrm{HPO}_{4}$ (Merck; 1.06580)) while gently shaking. The mixture is incubated at room temperature for $1 \mathrm{~min}$ and is then added drop by drop to the cells. $0.1 \mu \mathrm{g}$ plasmid DNA was used per square centimeter of cell culture. After $12 \mathrm{~h}$, cells are washed once with warm PBS and put into fresh medium at $37{ }^{\circ} \mathrm{C}$ under $5 \%(v / v)$ $\mathrm{CO}_{2}$ for at least 24 more hours.

\subsection{Cell Lysis of Transfected Cells for Co-Immunoprecipitation of HA Tagged Hsp90 $\beta$}

SILAC and non-SILAC HEK293T-Hsp90ßKO19 cells transfected with pCMV3-HAHsp90 $\beta^{\text {WT }}$, pCMV3-HA-Hsp90 $\beta^{\mathrm{S} 226 \mathrm{~A} / \mathrm{S} 255 \mathrm{~A}}$, or pCMV3-no tag-Hsp90 $\beta$ were harvested $36 \mathrm{~h}$ post-transfection using trypsin-EDTA (Thermo Fischer Scientific; 25200-056), washed twice with cold PBS, and frozen in liquid nitrogen. The obtained cell pellets are lysed in 2.5 volumes "NP40 lysis buffer" (1\% NP40 (Merck; 74385), 20 mM HEPES pH 7.5, $50 \mathrm{mM} \mathrm{KCl}$ (Merck; P4504), 5 mM MgCl 2 (PanReac AppliChem, Darmstadt, Germany; A1036) with protease (Roche, Mannheim, Germany; 04693159001) and phosphatase (Roche; 04906837001) inhibitors added) during $30 \mathrm{~min}$ incubation on ice with periodic vortexing. Extracts are centrifuged at $16,000 \times g$ for $10 \mathrm{~min}$ at $4{ }^{\circ} \mathrm{C}$. Supernatants are then collected, total protein content quantified by Pierce protein assay (Thermo Fisher Scientific; 22660) and expression of transfected protein measured by capillary western blot (CWB) on a JESS instrument (ProteinSimple, San Jose, CA, USA). HA tag quantification was carried out with an anti-HA antibody (BioLegend, San Diego, CA, USA; 901502) and fluorescence detection using default parameters provided by the manufacturer.

\subsection{Analysis of Extracts of Transfected HEK293T-Hsp90ßKO19 Cells ("Input" of Co-immunoprecipitations)}

For input analysis, $50 \mu \mathrm{g}$ of the same protein extracts used for co-immunoprecipitations were diluted $10 \times$ in "miST lysis buffer" (1\% sodium deoxycholate (Merck; 30970$), 30 \mathrm{mM}$ Tris (PanReac AppliChem; A1086) pH 8.6, 10 mM DTT (PanReac AppliChem; A1101)) and digested with trypsin and LysC with a protocol adapted from Kulak et al. ("miST digestion protocol") [51]. For SILAC samples, WT and AA were mixed in the dilution. Briefly, samples are boiled at $95^{\circ} \mathrm{C}$ for $5 \mathrm{~min}$, then reduction and alkylation of cysteines is done by adding $32 \mathrm{mM}$ chloroacetamide (Merck; C0267) and incubating for $45 \mathrm{~min}$ 
at room temperature in the dark. Samples are then each digested during $2 \mathrm{~h}$ at $37{ }^{\circ} \mathrm{C}$ with a first addition of trypsin/LysC mix (Promega, Madison, WI, USA; V5073) at the beginning and a second addition of trypsin/LysC mix after one hour of digestion. After digestion, 2 volumes of 1\% trifluoroacetic acid (TFA; Merck; 91699) in isopropanol (Merck; 19516) are added and the mixture is vortexed $10 \mathrm{~s}$ before centrifugation at $2300 \times g$ for $30 \mathrm{~s}$. The peptides are then desalted on MCX Oasis columns (Waters, Milford, MA, USA; 186001830BA) thrice with 1\% TFA in isopropanol and once with "solvent A" (2\% $(v / v)$ acetonitrile (Merck; 1.00029), 0.1\% (v/v) formic acid (Merck; 1.00264)). Peptides are then eluted in three steps with first $200 \mu \mathrm{L}$ "SCX125 buffer" (125 mM ammonium acetate (Merck; $73594), 0.5 \%(v / v)$ formic acid, 20\% (v/v) acetonitrile), second with $200 \mu \mathrm{L}$ "SCX500 buffer" (500 $\mathrm{mM}$ ammonium acetate, $0.5 \%(v / v)$ formic acid, 20\% $(v / v)$ acetonitrile), and third with $200 \mu \mathrm{L} 0.25 \% \mathrm{NH}_{3}$ (Merck; 5432) in 80\% (v/v) acetonitrile. Peptides are dried in a speedvac and finally resuspended in "HPLC loading buffer" $(2 \%(v / v)$ acetonitrile, $0.05 \%(v / v)$ TFA) before injection.

For LC-MS/MS analysis, samples were injected on an Orbitrap Fusion Tribrid mass spectrometer (Thermo Fisher Scientific) interfaced through a nano-electrospray ion source to an Ultimate 3000 RSLCnano HPLC system (Dionex, Sunnyvale, CA, USA). Peptides were separated on a reversed-phase custom packed 40 cm C18 column $(75 \mu \mathrm{m} \mathrm{ID,} 100 \AA$ A, Reprosil Pur $1.9 \mu \mathrm{m}$ particles, Dr. A. Maisch HPLC GmbH, Ammerbuch-Entringen, Germany) with a $4-76 \%$ acetonitrile gradient in $0.1 \%$ formic acid (140 min gradient except for SILAC samples separated by 95 min gradient). Full MS survey scans were performed at 120,000 resolution. A data-dependent acquisition (DDA) method, controlled by Xcalibur software (Thermo Fisher Scientific), was used to select precursors in "top speed" mode with a cycle time of $0.6 \mathrm{~s}$. Masses are isolated with a window of $1.6 \mathrm{~m} / \mathrm{z}$, fragmentation done in HCD mode with $32 \%$ energy, and fragments analyzed in the ion trap. Peptides selected for MS/MS were excluded from further fragmentation during $60 \mathrm{~s}$.

\subsection{Co-Immunoprecipitation (Co-IP) of HA Tagged Hsp90ß and Sample Preparation for Mass Spectrometry (Interactome) Analysis}

For label-free experiments, $500 \mu \mathrm{g}$ of total protein extract was mixed with $10 \mu \mathrm{g}$ antiHA antibody (BioLegend; 901502) and diluted to $150 \mu \mathrm{L}$ with "NP40 lysis buffer" and incubated at $4{ }^{\circ} \mathrm{C}$ overnight on a rotator. Antibody-protein complexes are purified next morning by adding $40 \mu \mathrm{L}$ of a 50\% proteinG coupled agarose beads slurry for $2 \mathrm{~h}$ (Merck; 17-0618-01). Beads are washed five times with "NP40 wash buffer" (0.01\% NP40, 20 mM HEPES pH 7.5, $50 \mathrm{mM} \mathrm{KCl,} 5 \mathrm{mM} \mathrm{MgCl}_{2}$ with protease and phosphatase inhibitors added) and immunopurified proteins are eluted with three consecutive incubations in $150 \mu \mathrm{L}$ $0.25 \% \mathrm{NH}_{3}$ for $15 \mathrm{~min}$ at $4{ }^{\circ} \mathrm{C}$. The three elutions are then pooled, dried in a speedvac, and resuspended in "miST lysis buffer" for subsequent "miST digestion protocol" but with only one final elution from the MCX Oasis columns with $200 \mu \mathrm{L} 0.25 \% \mathrm{NH}_{3}$ in $80 \%(v / v)$ acetonitrile.

For the SILAC experiment, the procedure is the same except that the heavy samples (WT) are pooled with the light samples (AA) into heavy/light replicates after eluting immunopurified proteins off the proteinG beads. No specific mixing ratio was used. Also, SILAC samples were eluted sequentially in two steps from the MCX Oasis columns using first $200 \mu \mathrm{L}$ "SCX125 buffer" and second with $200 \mu \mathrm{L} 0.25 \% \mathrm{NH}_{3}$ in $80 \%(v / v)$ acetonitrile. The peptides were then dried in a speedvac and resuspended in "HPLC loading buffer" before injection.

For LC-MS/MS analysis, samples were injected as described for the label free input samples.

\subsection{Mass Spectrometry Data Analysis of HA-Hsp90 $\beta^{W T} / H A-H s p 90 \beta^{S 226 A / S 255 A} / H s p 90 \beta^{W T}$ Co-Immunoprecipitation Experiments and Inputs}

MS data were processed by the MaxQuant software (version 1.6.3.4) incorporating the Andromeda search engine [52,53]. The UNIPROT human reference proteome database of October 2017 was used (71,803 sequences), supplemented with sequences of common 
contaminants. FDR filtering of both peptide and protein identifications was $1 \%$ with default MaxQuant parameters. Searches allowed for two missed cleavages and protease specificity set to trypsin $(K, R)$ with cleavage after prolines included. Carbamidomethyl on cysteines was set as fixed modification and oxidation on methionines and acetyl at the protein N-terminal as variable modification. Initial mass precursor tolerance is $20 \mathrm{ppm}$ and is then dynamically adjusted by MaxQuant after recalibration to about 5-6 ppm, and fragment mass tolerance is set at $0.5 \mathrm{Da}$. For SILAC, sample multiplicity was set to 2 with ${ }^{13} \mathrm{C}(6){ }^{15} \mathrm{~N}(2)$ as label for lysines and ${ }^{13} \mathrm{C}(6){ }^{15} \mathrm{~N}(4)$ for arginines. For label-free protein quantification, either the iBAQ values (for co-immunoprecipitation (co-IP) data) or the LFQ label-free (for input data) parameter were used [54]. For SILAC, the normalized H/L ratios were used for quantification, and these were aligned on the ratio of Hsp90 $\beta$ for co-IP data. Values were $\log _{2}$ transformed and normalized when needed.

The MaxQuant output file proteinGroups.txt was further analyzed with the R software, GO enrichment analysis was done with the $\mathrm{R}$ package clusterProfiler, and figures were produced with the ggplot2 package and Inkscape [55-85]. Protein groups labeled as reverse hits, only identified by site, and potential contaminants were removed. Protein groups with less than two unique peptides, four peptides, or six MS/MS counts in total were also removed. For the co-IP samples, we excluded from further analysis the proteins that were not identified by MS/MS in all six replicates in at least one condition for the label-free experiments, and in all replicates for the SILAC experiment. The co-IP data was then analyzed using $\log _{2}$ transformed and bait normalized iBAQ values or $\mathrm{H} / \mathrm{L}$ ratios. Missing iBAQ values were imputed only in co-IP negative control samples, in order to carry out a Student's $t$-test with Benjamini-Hochberg correction between the wild type or double mutant samples and the control samples. Our criteria for interactor validation were an adjusted $p$-value under 0.05 and a minimal average fold-change of 3 in $\log _{2}$ scale between the WT or AA mutant samples and the negative control samples. For GO term enrichment analysis, we selected the specific interactors with a positive or negative fold change and compared them to the complete list of proteins identified in the input.

\subsection{Total Hsp90ß Occupancy Protocol}

The prepared cell pellets (see mammalian cell culture) were lysed with 4 volumes "Total lysis buffer" (TLB; $50 \mathrm{mM}$ Tris- $\mathrm{HCl} \mathrm{pH}$ 7.4, $500 \mathrm{mM} \mathrm{NaCl}$ (Merck; 1.06404), 0.2\% (w/v) SDS (PanReac AppliChem; A3942), 10 mM sodium azide (Merck; 71289), with phosphatase and protease inhibitors added) for 1 volume pellet (volume units refer to initial pellet volume). The pellet is briefly vortexed, 0.4 volume Triton X-100 (Merck; 9002-93-1) 20\% (v/v) is added, the lysate is sonicated a first time on a Fisherbrand FB120 sonicator (1 min total, $1 \mathrm{~s}$ on $/ 1 \mathrm{~s}$ off pulses, $30 \%$ amplitude), 3.6 volumes of Tris- $\mathrm{HCl} 50 \mathrm{mM} \mathrm{pH} 7.4$ are added and the lysate is sonicated a second time ( $30 \mathrm{~s}$ total, $1 \mathrm{~s}$ on/off pulses, $30 \%$ amplitude).

For Hsp90ß purification, $100 \mu \mathrm{L}$ lysate was mixed with $900 \mu \mathrm{L}$ Tris- $\mathrm{HCl} 50 \mathrm{mM} \mathrm{pH}$ 7.4 and $4 \mu \mathrm{g}$ F-8 antibody (Santa Cruz Biotechnology Inc., Dallas, TX, USA; sc-13119X) was added for overnight immunoprecipitation. $40 \mu \mathrm{L}$ of a $50 \%$ slurry of protein-G coupled agarose beads is added the next day for 2 more hours. Beads are then washed 5 times with $500 \mu \mathrm{L}$ occupancy wash buffer (OWB; $0.01 \%(w / v)$ SDS, $25 \mathrm{mM} \mathrm{NaCl}, 50 \mathrm{mM}$ Tris- $\mathrm{HCl}$ $\mathrm{pH} 7.4$, with protease and phosphatase inhibitors). In case of the heavy labeled K562 cells, used as dephosphorylated samples, washes were done as follows: 2 washes with $500 \mu \mathrm{L}$ OWB, 2 washes with $200 \mu \mathrm{L}$ CutSmart buffer (New England BioLabs, Ipswich, MA, USA; B7204S) supplemented with protease inhibitors. On-beads dephosphorylation of Hsp90 was done by adding $200 \mu \mathrm{L}$ CutSmart buffer with $1 \mu \mathrm{L}$ CIP phosphatase (New England BioLabs; M0290) and incubating at $37^{\circ} \mathrm{C}$ for $30 \mathrm{~min}$, followed by 3 washes with $500 \mu \mathrm{L}$ OWB. All beads were eluted by adding $50 \mu \mathrm{L}$ SDS-PAGE sample buffer $2 \times(0.8 \%$ SDS, 20 mM Tris-HCl pH 6.8, 10\% glycerol (PanReac AppliChem; A0970), 2\% $\beta$-mercaptoethanol (Merck; 63689)).

For SDS-PAGE, $25 \mu \mathrm{L}$ of eluate of the samples of interest were mixed with $25 \mu \mathrm{L}$ of the dephosphorylated samples and the whole run on a 10\% SDS-PAGE at 130 V. Staining was 
done with G250 Coomassie (50\% (v/v) ethanol (ReactoLab SA, Servion, Switzerland; 15058), $10 \%(v / v)$ acetic acid (Carlo Erba Reagents, Val de Reuil, France; 401391), 0.25\% (w/v) coomassie blue (Merck; B0770)). Gel bands were excised from $75 \mathrm{kDa}$ to $150 \mathrm{kDa}$ and destained with $50 \mathrm{mM}$ ammonium bicarbonate (Merck; 09830) in 30\% (v/v) acetonitrile. Reduction and alkylation is done in $40 \mathrm{mM}$ chloroacetamide, $10 \mathrm{mM}$ TCEP (Merck; 93284), $50 \mathrm{mM}$ ammonium bicarbonate at $45{ }^{\circ} \mathrm{C}$ for $1 \mathrm{~h}$. Gel bands are then briefly washed with excess $50 \mathrm{mM}$ ammonium bicarbonate, dehydrated with excess acetonitrile, and left to dry completely under ventilation. Digestion is done in $100 \mu \mathrm{L} 50 \mathrm{mM}$ ammonium bicarbonate with $0.5 \mu \mathrm{g}$ trypsin (Promega; V5113) and $0.25 \mu \mathrm{g}$ LysC (Promega; V1671) at $37^{\circ} \mathrm{C}$ overnight. Peptides are extracted next day by incubating the gel bands with $100 \mu \mathrm{L} 10 \%$ formic acid for 20 min first, and then 20 more minutes with $200 \mu \mathrm{L}$ acetonitrile. Peptide extracts were pooled by sample, frozen in liquid nitrogen and dried under vacuum in a speedvac. The dried peptides are then resuspended in $30 \mu \mathrm{L}$ "HPLC loading buffer".

For LC-MS/MS analysis, $5 \mu \mathrm{L}$ of sample was injected on the same instruments as for the co-IP experiments. The LC separation was done as described for the co-IP experiments but with a 95 min gradient. The mass spectrometer was operated in parallel reaction monitoring (PRM) mode, controlled by Xcalibur software. The list of peptides, masses, ion targets, maximum ion injection times for the monitored peptides are given in Table S1 (time windows were continuously adjusted depending on the LC column used). The Hsp90 $\beta$ normalization peptides were selected among the unique peptides with retention times higher than CL peptides. Two CL peptides were selected for each phosphosite: one without missed cleavage, and another with one or two missed cleavage in the vicinity of (potential) phosphosites that could inhibit trypsin. Masses are isolated with a window of $1.6 \mathrm{~m} / \mathrm{z}$, fragmentation done in HCD mode with 32\% energy, and fragments analyzed in an orbitrap with 30,000 resolution. Full MS survey scans are taken every $1.5 \mathrm{~s}$ with 120,000 resolution. Peptide identification is then carried out with Mascot Server 2.6 (Matrix Science, London, UK) with the following parameters: protease specificity set to trypsin with cleavage after prolines included, maximum two missed cleavages, carbamidomethyl on cysteines as fixed modification, ${ }^{13} \mathrm{C}(6){ }^{15} \mathrm{~N}(2)$ on lysines, ${ }^{13} \mathrm{C}(6){ }^{15} \mathrm{~N}(4)$ on arginines, and phosphorylation on serines and threonines as variable modifications, $10 \mathrm{ppm}$ mass tolerance on the precursor, 0.02 Da mass tolerance on fragment, threshold score at $p<0.05$ ) [86]. Peptide quantification was done manually in Skyline on the extracted ion chromatograms of fragments $[87,88]$.

Occupancy was calculated as described by Olsen et al. [89]. Briefly, the H/L ratios of the phosphopeptide $(x)$, the unmodified peptide $(y)$, and the whole protein $(z$; derived from normalization peptides) are used to compute $\mathrm{a}$ and $\mathrm{b}$ values according to the following formulas:

$$
a=\frac{(z-y)}{(x-z)} ; \quad b=\left(\frac{x}{y}\right)^{*}
$$

a. Occupancy is then calculated in the light sample using value a and in the heavy sample using value $b$ according to the following formulas:

b. $\quad$ Occupancy light $_{1}=\frac{a}{(a+1)} ;$ Occupancy $_{\text {heavy }}=\frac{b}{(b+1)}$

\subsection{Nuclear and Extracellular Hsp90ß Occupancy Protocol}

For nuclear occupancy, 1 volume of K562 cells was lysed in three volumes of cytosolic extraction buffer (CEB; 10 mM HEPES pH 7.4, $10 \mathrm{mM} \mathrm{KCl,} 2 \mathrm{mM} \mathrm{MgCl} 2,0.01 \%$ (v/v) NP40, with protease and phosphatase inhibitors added). The lysate is passed through a 25 ga needle three times and vortexed for $5 \mathrm{~min}$ at $4{ }^{\circ} \mathrm{C}$. After 15 more minutes incubation on ice, the lysate is centrifuged $5 \mathrm{~min}$ at $800 \times \mathrm{g}$ at $4{ }^{\circ} \mathrm{C}$. The supernatant is transferred to a new tube and is the cytosolic extract; the resulting pellet is washed with the same volume of CEB, passed through a 25 ga needle once, and centrifuged again, $10 \mathrm{~min}$ at $800 \times g$ at $4{ }^{\circ} \mathrm{C}$. Supernatant is discarded, the pellet is lysed with 2 initial cell pellet volumes of TLB, and then the same lysis and subsequent Hsp90 $\beta$ purification, SDS-PAGE, digestion and LC-MS/MS analysis procedures are used as in the total Hsp90 $\beta$ occupancy protocol. 
For extracellular occupancy, three $50 \mathrm{~mL}$ cultures of isotopically, heavy labeled K562 cells at 0.6 million $/ \mathrm{mL}$ density were used. Conditioned mediums were centrifuged at $100 \times \mathrm{g}$ for $10 \mathrm{~min}$ at $4{ }^{\circ} \mathrm{C}$, and the supernatant transferred to a new tube and centrifuged again. The medium was then concentrated on $30 \mathrm{~K}$ Amicon $15 \mathrm{~mL}$ filters (Merck; UFC905008) down to $750 \mu \mathrm{L}$ and transferred to a new tube. Filter walls were washed with $750 \mu \mathrm{L}$ "NP40 lysis buffer" and pooled with the concentrated medium. The obtained concentrated mediums were pre-cleared with additions of $40 \mu \mathrm{L}$ of a $50 \%$ slurry of protein $\mathrm{A}$ coupled agarose beads, and $40 \mu \mathrm{L}$ of a $50 \%$ slurry of protein $\mathrm{G}$ coupled agarose beads for 20 min. Subsequent Hsp90 $\beta$ purification, SDS-PAGE, digestion and LC-MS/MS analysis, and data analysis procedures were done as in the total Hsp90 $\beta$ occupancy protocol.

\subsection{Limted Proteolysis with Trypsin}

The samples were prepared partly as described by Tsutsumi et al. [18]. Briefly, HEK293T-Hsp90ßKO19 cells were transiently transfected with plasmids expressing either HA-Hsp $90^{\text {WT }}$, HA-Hsp90 $\beta^{\text {S226A/S255A }}$ or without plasmid as control as described above. Lysis and IP is done as for the interactome co-IP experiments until the beads washes. Here, beads are washed twice with $500 \mu \mathrm{L}$ "NP40 wash buffer", and then 3 times with $500 \mu \mathrm{L}$ "NP40 wash buffer" supplemented with $500 \mathrm{mM} \mathrm{NaCl}$ but without protease inhibitors. During the last wash, the beads are equally split in 3 fractions. Then, $40 \mu \mathrm{L}$ ice cold $50 \mathrm{mM}$ ammonium bicarbonate with either 0,7 , or $14 \mathrm{ng} / \mu \mathrm{L}$ trypsin are added to the beads and incubated for $6 \mathrm{~min}$ on ice. The reaction is stopped by adding $15 \mu \mathrm{L}$ SDS-PAGE sample buffer $5 \times$ and heating at $95^{\circ} \mathrm{C}$ for $5 \mathrm{~min}$.

CWB analysis was done on a JESS instrument as for the HA-tag expression control of transfected cells with the exception that HA-tag was quantified by an anti-HA antibody conjugated to HRP (Roche; 12013819001) diluted 1:100.

For SDS-PAGE, $20 \mu \mathrm{L}$ of sample was run on a $6 \%$ SDS-PAGE at $130 \mathrm{~V}$, and the lanes cut in 8 gel pieces from band A to $40 \mathrm{kDa}$. Digestion of the samples was done as described previously [90].

For LC-MS/MS analysis, samples were injected on a Thermo Fischer Scientific QExactive Plus mass spectrometer (Thermo Fisher Scientific) interfaced through a nanoelectrospray ion source to an Ultimate 3000 RSLCnano HPLC system (Dionex). Peptides were separated on a reversed-phase custom packed 40 cm C18 column (75 $\mu \mathrm{m}$ ID, $100 \AA$, Reprosil Pur $1.9 \mu \mathrm{m}$ particles, Dr. A. Maisch HPLC GmbH) with a $4-76 \%$ acetonitrile gradient in $0.1 \%$ formic acid of $65 \mathrm{~min}$. Full MS survey scans were performed at 70,000 resolution. The mass spectrometer was operated in data-dependent acquisition (DDA) "Top10" mode, controlled by Xcalibur software. Masses are isolated with a window of $1.5 \mathrm{~m} / \mathrm{z}$, and fragments analyzed in an orbitrap with 17,500 resolution. Peptides selected for MS/MS were excluded from further fragmentation during $60 \mathrm{~s}$. Peptide identification is then carried out with Mascot Server 2.6 (Matrix Science) with the following parameters: protease specificity set to trypsin with cleavage after prolines included, maximum six missed cleavages, carbamidomethyl on cysteines as fixed modification, oxidation on methionines and phosphorylation on serines and threonines as variable modifications, $10 \mathrm{ppm}$ mass tolerance on the precursor, 0.02 Da mass tolerance on fragment, threshold score at $p<0.05$ ). Peptide quantification was subsequently done manually in Skyline on the extracted ion chromatograms of selected precursors.

\subsection{Analysis of Mutant Secretion}

HEK293T-Hsp90ßKO19 cells were transiently transfected with plasmids expressing either HA-Hsp90 $0^{\mathrm{WT}}$, HA-Hsp $90 \beta^{\mathrm{S} 226 \mathrm{~A} / \mathrm{S} 255 \mathrm{~A}}$ or without plasmid as control as described above. $24 \mathrm{~h}$ after PBS wash, the medium was collected and the cells harvested.

Samples were prepared partly as described by Cortes et al. [91]. Briefly, $10 \mathrm{~mL}$ medium was spun at $100 \mathrm{~g}$ for $10 \mathrm{~min}$ at $4{ }^{\circ} \mathrm{C}$ and concentrated down to $100 \mu \mathrm{L}$ on $30 \mathrm{~K}$ Amicon $5 \mathrm{~mL}$ filters (Merck; UFC803024). Concentrated medium was transferred to a new tube and filter walls were washed with $100 \mu \mathrm{L}$ "NP40 lysis buffer" and pooled with concentrated medium. 
The concentrated medium was then denatured by adding $60 \mu \mathrm{L}$ SDS-PAGE sample buffer $5 \times$ and heating at $95^{\circ} \mathrm{C}$ for $5 \mathrm{~min}$. Harvested cells were lysed as for the co-IP experiments.

Samples were analyzed by CWB on a JESS instrument with default parameters. HAtag was quantified as for the expression controls of the transfected cells and $\beta$-actin was quantified using a $\beta$-actin antibody (Bio-Techne, Minneapolis, MN, USA; MAB8929) and chemiluminescence detection.

\subsection{Cell Treatment and Sample Preparation for Phosphorylation Analysis ( $\mathrm{TiO}_{2}$ Enrichment)}

For heat shock treatment, $\mathrm{K} 562$ cells were resuspended in $2 \mathrm{~mL}$ medium at $37^{\circ} \mathrm{C}$ or $42{ }^{\circ} \mathrm{C}$ at a density of 5 million/mL and incubated for $15 \mathrm{~min}, 1 \mathrm{~h}$, and $3 \mathrm{~h}$ in a $37^{\circ} \mathrm{C}$ humidified incubator or at $42^{\circ} \mathrm{C}$ in a water bath. The cells were then immediately washed with $48 \mathrm{~mL}$ cold PBS and frozen in liquid nitrogen.

For Hsp90 inhibitors treatment, three $150 \mathrm{~cm}^{2}$ culture flasks with each 30 million K562 cells at 1 million/mL density were supplemented with 160 nM Ganetespib (Selleck Chemicals, Houston, TX, USA), 620 nM 17-DMAG (Selleck Chemicals), or 1\% (v/v) DMSO as control, and a third of each culture was taken after $15 \mathrm{~min}, 1 \mathrm{~h}$, and $3 \mathrm{~h}$ of treatment. Cells were then immediately centrifuged and washed with $50 \mathrm{~mL}$ cold PBS before freezing in liquid nitrogen.

For serum starvation, acidosis, and $\mathrm{H}_{2} \mathrm{O}_{2}$ treatment, $\mathrm{K} 562$ cells from a 0.5 million/mL density culture were transferred into control RPMI1640 with 10\% FBS or into RPMI1640 without FBS for serum starvation, or into RPMI1640 with 10\% FBS at pH 6 for acidosis, or into RPMI1640 with 10\% FBS and 1 mM hydrogen peroxide (Merck; 95321) for $\mathrm{H}_{2} \mathrm{O}_{2}$ treatment, and incubated for 6 and $24 \mathrm{~h}$ (for $\mathrm{H}_{2} \mathrm{O}_{2}$ treatment, $6 \mathrm{~h}$ only).

Treated cells were lysed in "miST lysis buffer" and proteins digested with the "miST digestion protocol" described above. A quarter of the digested sample is used as is for input analysis and is resuspended in "HPLC loading buffer". The rest of the sample is used for titanium-dioxide phosphopeptide enrichment. The peptides are desalted on a Sep-Pak tC18 $\mu$ Elution plate (Waters) and eluted into "TiO loading buffer" (80\% $(v / v)$ acetonitrile, $2.5 \%(v / v)$ TFA, $80 \mathrm{mg} / \mathrm{mL}$ glycolic acid (Merck; 124737)). For every $10 \mu \mathrm{g}$ of digested peptides, $1 \mu \mathrm{L}$ of a $\mathrm{TiO}_{2}$ beads (ZirChrom Separations Inc., Anoka, MN, USA) slurry at $100 \mathrm{mg} / \mathrm{mL}$ is added and incubated for $15 \mathrm{~min}$ on a wheel at $4{ }^{\circ} \mathrm{C}$. The beads are then centrifuged and washed as follows, with each wash using $200 \mu \mathrm{L}$ and followed by $5 \mathrm{~min}$ vortexing and short centrifugation: two washes with "TiO loading buffer", two washes with "Wash buffer 1" (70\% (v/v) acetonitrile, 0.1\% $(v / v)$ TFA, $80 \mathrm{mg} / \mathrm{mL}$ glycolic acid), two washes with "Wash buffer 2" (70\% (v/v) acetonitrile, 0.1\% (v/v) TFA), two washes with "Wash buffer 3" $(0.1 \%(v / v)$ TFA). Enriched peptides are then recovered with two consecutive incubations for $5 \mathrm{~min}$ in "TiO elution buffer" (50 $\mathrm{mM} \mathrm{Na}_{2} \mathrm{HPO}_{4}, 5 \mathrm{mM} \mathrm{Na}_{3} \mathrm{VO}_{4}$ (Merck; S6508), $1 \mathrm{mM} \mathrm{NaF}$ (Merck; 201154)). Eluates are finally acidified with formic acid and 20\% TFA before injection.

Inputs and enriched phosphopeptides were analyzed by LC-MS/MS with the same method as described for the co-IP experiments, except that the enriched phosphopeptides were analyzed in "top speed" mode with $1.5 \mathrm{~s}$ cycling time and the fragments were detected in the orbitrap with 15,000 resolution. Peptide identification was then carried out with Mascot Server 2.6 (Matrix Science) with the following parameters: protease specificity set to trypsin with cleavage after prolines included, maximum nine missed cleavages, carbamidomethyl on cysteines as fixed modification, phosphorylation on serines and threonines as variable modifications (plus acetyl at protein N-terminal and oxidation on methionines as variable modifications for input samples), $10 \mathrm{ppm}$ mass tolerance on the precursor, 0.02 Da mass tolerance on fragment for enriched phosphopeptides samples and 0.5 Da mass tolerance on fragments for input samples, threshold score at $p<0.05$ ). Peptide quantification was subsequently done manually in Skyline on the extracted ion chromatograms of selected precursors. 


\subsection{Mutant ATP and ADP Binding Analysis with Active Site Probes}

HEK293T-Hsp90ßKO19 cells were transfected as described with WT and AA plasmids. Protein extraction, sample preparation and ATP and ADP binding was done using the Pierce $^{\mathrm{TM}}$ Kinase Enrichment Kit (Thermo Fisher Scientific; 1862511) and the ActivX ${ }^{\mathrm{TM}}$ desthiobiotin-ATP and -ADP probes (Thermo Fisher Scientific; 88311, 88313). Instead of purifying labeled proteins with beads binding to desthiobiotin, the transfected proteins were purified by immunoprecipitation with $1 \mu \mathrm{g}$ HA antibody per $100 \mu \mathrm{g}$ of protein extract for $1 \mathrm{~h}$ and $30 \mathrm{~min}$. Antibody-protein complex were recovered by addition of a $50 \%$ protein $\mathrm{G}$ beads slurry for $1 \mathrm{~h}$ and $20 \mathrm{~min}$ and beads were washed three times with OWB. Purified proteins were eluted by adding SDS-PAGE sample buffer $2 \times$ to the beads and boiling $5 \mathrm{~min}$ at $95^{\circ} \mathrm{C}$. The obtained samples were then analyzed by CWB on a JESS instrument with default parameters. HA tag quantification was carried out with an anti-HA antibody (BioLegend; 901502) and fluorescence detection and desthiobiotin was quantified with streptavidin-HRP (ProteinSimple; 042-414) and chemiluminescence detection.

\subsection{Raw LC-MS/MS Data Availability}

The mass spectrometry proteomics data for the co-IP experiments have been deposited to the ProteomeXchange Consortium via the PRIDE partner repository with the dataset identifier PXD025873 (username: reviewer_pxd025873@ebi.ac.uk, password: gtQBiP4Z) [92,93]. Identifier for data for occupancy measurements and phosphorylation comparison in stressed cells are PXD025888, doi:10.6019/PXD025888 (username: reviewer_pxd025888@ebi.ac.uk, password: zmpKajPr). For the trypsin sensitivity experiment data, identifier are PXD025878 and doi:10.6019/PXD025878 (username: reviewer_pxd025878@ebi.ac.uk, password: blo60H4K). Login to access the data is through www.ebi.ac.uk/pride, accessed on 17 May 2021.

\section{Results}

\subsection{High Phosphorylation Occupancy for Both S226 and S255 in Hsp90ß in a Range of Cell Lines}

Determining the occupancy of a post-translational modification (PTM) by liquid chromatography coupled to tandem mass spectrometry (LC-MS/MS) requires the measurement of both the modified and unmodified peptides in two samples with different occupancy. The digestion of the CL with trypsin or LysC for LC-MS/MS is incomplete due to the inhibitory presence of numerous negatively charged residues (Figure 1A,B) [94]. This results in a mixture in which we chose to measure two peptides for each S226 and S255: one without missed cleavage, and one with a single or more missed cleavage(s) in the vicinity of phosphosites that may inhibit trypsin or LysC (Figure 1B). A set of other Hsp90 peptides (Figure 1C) were used for normalization. We used Stable Isotope Labeling with Amino acids in Cell culture (SILAC) and compared Hsp90 $\beta$ purified from unlabeled (light) cells with Hsp90 $\beta$ purified from heavy labeled cells and treated with phosphatase. Light and heavy samples were mixed together prior to digestion to ensure identical digestion efficiency. We tested our set-up with synthetic peptides spanning S226 and S255, and we also controlled for the presence of peptides with phosphorylation on S261, that we determined as negligible for our purposes (Table S2, sheet "Hsp90-S255-S261-Checks"). 


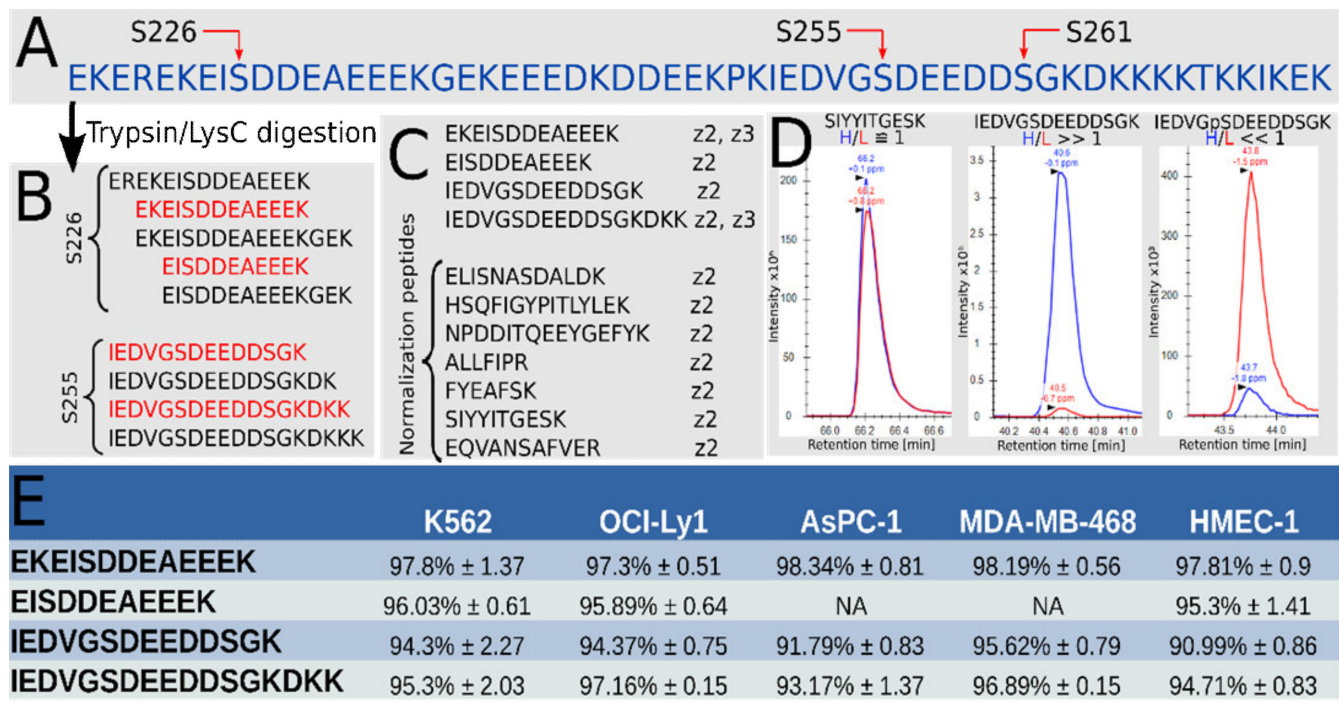

Figure 1. Determination of occupancy of CL phosphosites in human Hsp90 $\beta$ (HSP90AB1). (A) Amino acid sequence of Hsp90 $\beta$ 's CL with S226, S255 and S261 indicated by red arrows. (B) Typical peptides spanning S226 or S255 resulting from a tryptic digestion of the CL. The peptides marked in red were selected for targeted MS. (C) The complete list of peptides selected for the targeted MS method and their charge state ( $\mathrm{z}$ number). Normalization peptides are required to determine the $\mathrm{H} / \mathrm{L}$ ratio for the whole protein. Both phosphopeptides and non-phosphopeptides from the CL were measured. (D) Typical chromatogram for a normalization peptide (here SIYYITGESK, left pane), a non-phosphopeptide from the CL (IEDVGSDEEDDSGK, middle pane), and its corresponding phosphopeptide (IEDVGpSDEEDDSGK, right pane). The chromatogram for the heavy $(\mathrm{H})$ peptide is the blue curve, and the light $(\mathrm{L})$ chromatogram the red curve. (E) Average and standard deviation of phosphorylation occupancy for 5 human cell lines $(n=3)$.

As shown in Figure 1D, left pane, the chromatograms for the heavy and light normalization peptides is expected to be similar, thus with a heavy to light ratio $(\mathrm{H} / \mathrm{L})$ close to 1 . For the non-phosphopeptides (Figure 1D, middle pane), we expect the heavy chromatogram to be more intense, since the heavy sample is dephosphorylated in vitro, and vice-versa for the phosphopeptide (Figure 1D, right pane). The phosphorylation occupancy is derived from these three ratios [89]. The results obtained for five human cell lines grown in standard conditions are shown in Figure 1E.

Our data suggests that about $95 \%$ of both sites are phosphorylated in all tested cell lines. This implies that at least $90 \%$ of Hsp $90 \beta$ monomers are phosphorylated on both S226 and S255 if phosphorylation is independent (90\% phosphorylated on both, $5 \%$ only on S226, 5\% only S255) and at most 95\% if it is coupled (95\% phosphorylated on both, 5\% not phosphorylated on both). We obtained very similar values in lines of breast cancer cells (MDA-MB-468), chronic myelogenous leukemia cells (K562), pancreatic adenocarcinoma cells (AsPC-1), diffuse large B-cell lymphoma (OCI-Ly1) and untransformed, primary mammary epithelial cells (HMEC). The latter have a much slower growth rate, indicating that high occupancy on S226 and S255 is not a unique feature of rapidly proliferating cancer cells.

We sought to determine the phosphorylation state of Hsp90 $\alpha$ as well, but digestion

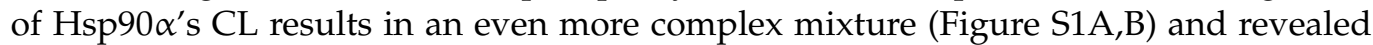
phosphorylation on S252 on the peptides comprising S263 (Figure S1C), complicating calculations. We were able to produce data suggesting a similarly high occupancy for S231 (Figure S1D), but it was not possible for S263.

In essence, our occupancy measurements indicate that phospho-occupancy at S226 and S255 on Hsp90 $\beta$ is constitutively high in several cultured cells under normal growth conditions. 


\subsection{Charged Linker Phosphorylation Remains High in Stressed and Heat Shocked Cells}

We treated K562 cells with heat shock, Hsp90 inhibitors, or stressed the cells by altering the growth conditions and compared them to untreated cells to see if CL phosphorylation correlates with Hsp90 activity. The input lysate was also analyzed to compensate for potential Hsp90 up- or downregulation.

Of all the conditions tested $\left(42{ }^{\circ} \mathrm{C}\right.$ heat shock; ganetespib treatment; 17-DMAG treatment; serum-starvation; cells grown in acidic conditions; oxidative stress by $\mathrm{H}_{2} \mathrm{O}_{2}$ added to medium), none resulted in a significant alteration of the CL's phosphorylation of any isoform (Table S3).

These results indicate that the phosphorylation of S226 and S255 remains stable in a variety of conditions that have an impact on Hsp90 activity and expression levels. As Hsp90 mostly exerts its function by binding to other proteins, we next studied the impact of CL phosphorylation on the Hsp90ß interactome.

\subsection{Mutation of S226 and S255 to Alanines Increases the Amount of Hsp90 $\beta$ Co-Purifying Proteins}

We compared the proteins interacting with "wild type" $\mathrm{Hsp} 90 \beta^{\mathrm{WT}}$ (further on referred to as "WT") and with a double Hsp90 $\beta^{\text {S226A/S255A }}$ alanine mutant (further on referred to as "AA") in which both S226 and S255 are mutated to alanines, by co-immunoprecipitation (co-IP) followed by LC-MS/MS. We voluntarily limited the comparison to a double mutant only, since our data indicate that roughly $90 \%$ of $\mathrm{Hsp} 90 \beta^{\mathrm{WT}}$ should be phosphorylated on both S226 and S255. The WT and AA protein have an HA tag at the N-terminal and were expressed in Hsp90 $\beta \mathrm{KO}$ cells, which allowed us to eliminate interference from WT endogenous Hsp90 $\beta$ that would most likely form heterodimers with mutants [48]. For negative control, we used WT Hsp90 without HA tag. The experiment was carried out twice, each time with 3 replicates.

The levels of bait and input proteins were comparable between the conditions (Figure S2A,B). The phosphorylation occupancy of S226 and S255 in the transfected WT Hsp90 $\beta$ protein was very close to the values normally observed for the endogenous protein (Figure S2C). We identified 315 specific interactors, including well-known Hsp90 $\beta$ interactors CDC37, Hsp70 (HSPA1), Hsc70 (HSPA8), Hsp40 (DNAJB1), and the glucocorticoid receptor, after application of stringent filtering criteria (Table S4).

We did not identify any protein interacting only with WT or AA. However, comparison of AA and WT co-IPs revealed substantial quantitative differences, as many proteins copurified in greater quantity with AA (Figure 2A, Figure S2D). To confirm this unexpected result, we repeated the experiment with SILAC labeling and four replicates to maximize quantitation accuracy. We focused data analysis on the the 315 specific interactors. This allowed us to use a more accurate SILAC duplex experiment with a direct comparison of WT (heavy sample) and AA (light sample).

Input lysates were comparable, but the expression of WT in the heavy cells was slightly higher than that of AA in the light cells (Figure S3A-D). Correspondingly, more WT was immunoprecipitated compared to AA (Figure S3E). Applying stringent filtering criteria, we found 83 out of the previously defined $315 \mathrm{Hsp} 90 \beta$ specific interactors that were identified and quantified in all four replicates of both WT and AA (Table S5). Unpaired $t$-test with Benjamini-Hochberg correction highlighted 69 regulated interactors $(p$-value $<0.05)$. 

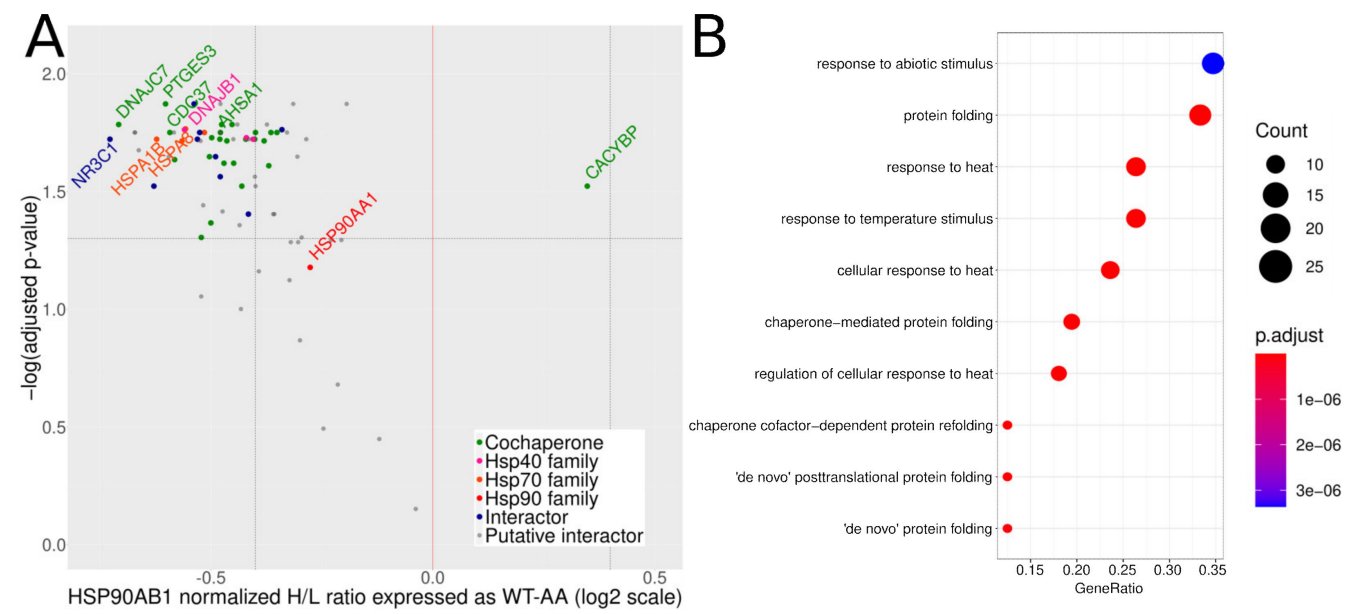

Figure 2. Quantitative exploration of the interactome of WT vs. AA. (A) Volcano plot of the inverse $\log _{10}$ of the adjusted $p$-value as a function of the normalized $\mathrm{H} / \mathrm{L}$ ratio in $\log _{2}$ scale for all 83 quantified interactors (SILAC experiment). Points represent individual proteins. Point color code: co-chaperones in green, Hsp40 proteins in pink, Hsp70 in orange, Hsp90 in red, other already known interactors in blue, and putative interactors in grey. Classification of co-chaperones and known interactors is based on the "Hsp90 interactors" table by Didier Picard (www.picard.ch, accessed on 17 May 2021). Horizontal dashed line marks the 0.05 threshold for the adjusted $p$-value, vertical dashed lines mark absolute fold-changes greater than 0.4, and vertical red line marks Hsp90ß. (B) Gene Ontology (GO) term analysis of the proteins enriched in the AA co-IP. Vertical axis: enriched GO terms. Horizontal axis: the GeneRatio is the ratio between the number of proteins enriched with the corresponding GO term and the total number of proteins identified in the input assigned to the corresponding GO term. Spot size is proportional to the count of proteins enriched (legend on the right of the plot). Spot color corresponds to the adjusted $p$-value as described in the color scale on the right of the plot.

The volcano plot for the SILAC experiment, in Figure 2A, shows that a lot of wellknown Hsp90ß interactors were more abundant in the AA co-IPs, and co-chaperones such as p23, DNAJC7, CDC37, AHSA1, as well as DNAJB1, HSPA1, HSPA8, and the client protein glucocorticoid receptor (NR3C1) were found among the most enriched proteins in the AA co-IPs (adjusted $p$-value $<0.05$ ). Even though the ratios were not very large in absolute terms, they were statistically significant. For abundant proteins like Hsp90 $\alpha$ or Hsp70/Hsc70, even such mild changes imply a large difference in the numbers of chaperone complexes impacted. Annotation enrichment analysis on the proteins with increased binding to AA highlighted the terms typically associated with the Hsp90 chaperone machine (Figure 2B, Figure S2E). The same analysis on the proteins with decreased binding to AA yielded no significant term. We did not detect significant differences in changes among the subgroups of Hsp90 interactors (as defined in Figure 2A). One notable exception was the co-chaperone CACYBP, which exhibited a behavior in stark contrast to all other co-chaperones, with a higher binding affinity for the phosphorylated (WT) form of Hsp90 $\beta$. Label-free and SILAC data thus both indicate that mutating S266 and S255 to alanines globally increases the amount of proteins co-purifying with Hsp90ß (Figure S3F). The broad but relatively mild impact of alanine mutations on the Hsp90 $\beta$ interactome suggests that these phosphosites alter general Hsp90 $\beta$ activity and conformation. We thus tested if the mutations affected ATP/ADP binding and Hsp90 $\beta$ sensitivity to tryptic cleavage.

\subsection{S226 and S255 Mutations to Alanine do Not Alter ATP/ADP Binding}

ATP / ADP binding was estimated for the WT Hsp90 $\beta$ and the AA mutant in crude cell extracts using Activ $X^{\mathrm{TM}}$ probes (which label ATP/ADP binding sites with desthiobiotin) and detecting desthiobiotinylation by capillary Western blot analysis (CWB). Such probes have already been used in competition assays to characterize the specificity of Hsp90 
inhibitors [95]. Table 2 summarizes the average and standard deviation (s.d.) of the desthiobiotin signal normalized by HA-tag signal, as well as the $p$-value resulting from a t-test comparing WT and AA values. Table S6 gives the signal intensities for desthiobiotin, HA-tag, and desthiobiotin normalized by HA-tag.

Table 2. Average and standard deviation (s.d.) of the desthiobiotin signal normalized by HA-tag signal.

\begin{tabular}{ccc}
\hline Sample & Average \pm s.d. & $p$-Value \\
\hline WT + ATP & $0.46 \pm 0.03$ & \\
AA + ATP & $0.53 \pm 0.05$ & ATP:0.12 \\
WT + ADP & $0.34 \pm 0.04$ & ADP:0.8 \\
AA + ADP & $0.35 \pm 0.06$ & \\
\hline
\end{tabular}

Both WT and AA showed greater affinity for ATP than ADP, and both appeared to be desthiobiotinylated to a similar extent. The average value for ATP binding by the AA mutant was somewhat higher than for WT, but the difference was not statistically significant, suggesting that S226 and S255 mutation to alanines does not have a dramatic effect on ATP/ADP binding.

\subsection{S226 and S255 Mutation to Alanine Enhances Tryptic Cleavage in the C Domain}

Sensitivity to proteolytic cleavage has been used to assess global changes in Hsp90 conformation [96]. Since the CL sequence has already been reported to affect Hsp90 $\beta$ 's sensitivity to tryptic cleavage, we investigated whether S226 and S255 mutation to alanines also had an effect [19].

CWB analysis suggests that WT is more resistant to tryptic cleavage than AA (Figure 3A), as the full-length double mutant bands intensities decrease more than WT with increasing trypsin concentration. Two cleavage products were detected near 60 and $80 \mathrm{kDa}$ with an anti-HA antibody (Figure S4), and as the HA-tag is at the N-terminal, these products were probably cleaved in the $\mathrm{C}$ domain. No other cleavage products were detected (analysis range was down to $12 \mathrm{kDa}$ ), the HA-tag being most likely cut off in these. The total HA signal of the full-length protein, the 80 , and the $60 \mathrm{kDa}$ products in the WT sample with $14 \mathrm{ng} / \mu \mathrm{L}$ trypsin is about $90 \%$ of the HA signal in the WT sample with $0 \mathrm{ng} / \mu \mathrm{L}$ trypsin, whereas this value drops to about $50 \%$ for AA, indicating increased tryptic cleavage near the HA-tag for AA, probably in the N domain. The full-length HA-Hsp $90 \beta$ bands' intensity in the samples with 7 and $14 \mathrm{ng} / \mu \mathrm{L}$ trypsin amounts to 55\% and $20 \%$ of the signal in the sample without trypsin for WT, respectively, and 30\% and 10\% for AA, respectively (Table S7).

SDS-PAGE analysis and Coomassie staining revealed other protein bands near 75, 65 , and $60 \mathrm{kDa}$ in the samples with trypsin (Figure 3B). Band A indicates full length HA-Hsp90ß. All bands were then trypsin digested and analyzed by LC-MS/MS.

Figure 3C gives the ratio of Hsp90 $\beta$ 's unique peptides MS intensity in gel band A divided by the initial intensity in band A with $0 \mathrm{ng} / \mu \mathrm{L}$ trypsin as a measure of full length Hsp $90 \beta$ cleavage. The data indicates that more full length AA was cleaved than WT: the peptides' intensities in the samples with 7 and $14 \mathrm{ng} / \mu \mathrm{L}$ trypsin amount to about 35\% and $10 \%$ of the intensity in the sample without trypsin for WT, respectively, and $22 \%$ and $6 \%$ for AA, which is in qualitative agreement with the CWB data.

Intensity analysis of peptides spanning Hsp90 $\beta$ from E42 to R679 in the cleavage products bands suggests that the main position where Hsp90 $\beta$ was cleaved is in the C domain (Table S8). K607 is a reported major tryptic cleavage site in Hsp90ß's C domain, resulting in $70 \mathrm{kDa}$ and $12 \mathrm{kDa}$ products (Figure 3D). Figure $3 \mathrm{E}$ gives the MS intensity of Hsp $90 \beta$ unique peptides in gel band A divided by their intensity in the whole lane. 

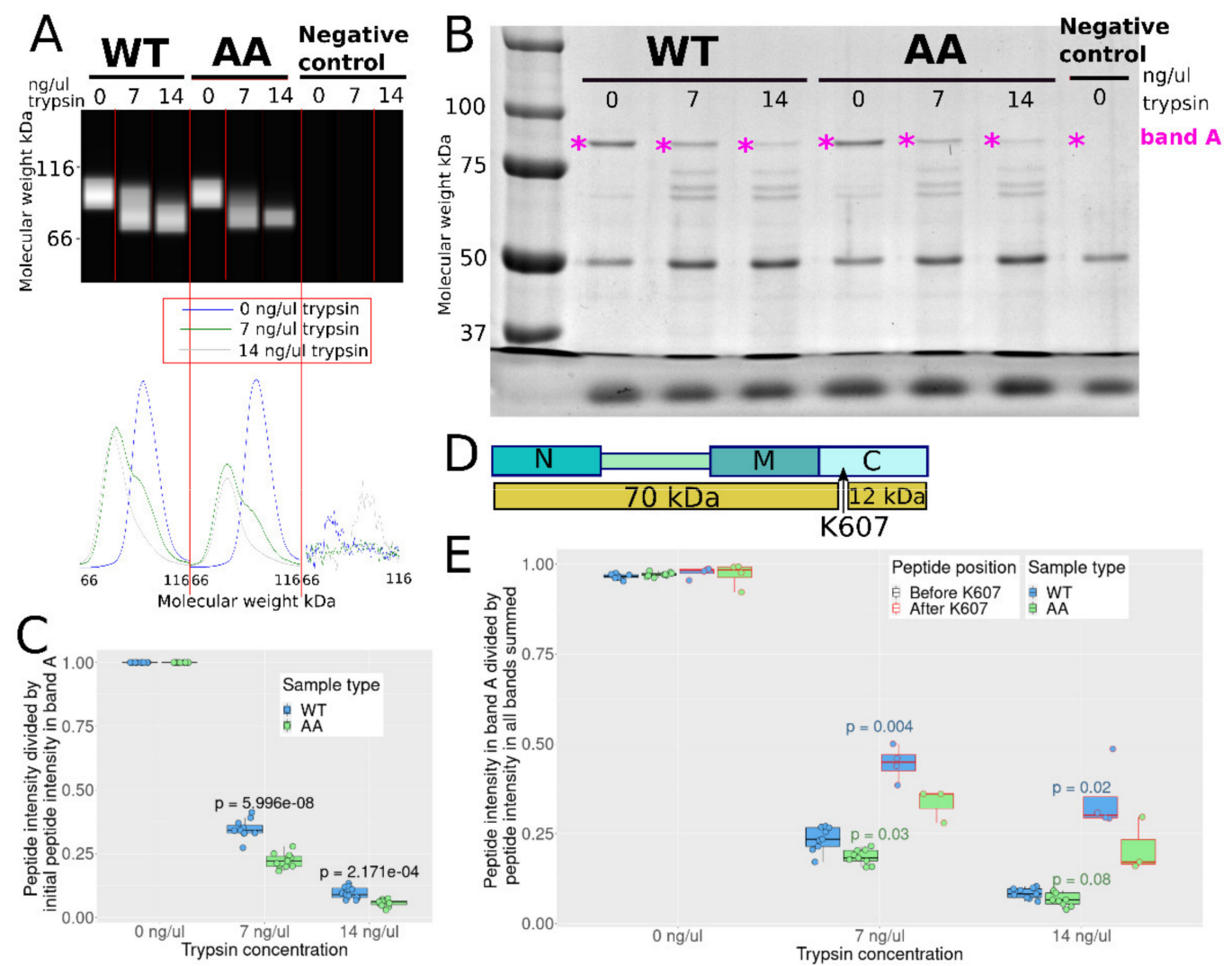

Figure 3. Sensitivity of WT and AA to limited proteolysis. (A) Reconstructed electropherogram of capillary western blot detection of HA-tag for WT and AA for increasing trypsin concentrations (top, dark background) and graph view below. (B) SDS-PAGE analysis of the trypsin cleavage products. Full-length Hsp90 is indicated by the pink star ("band A"). (C) Boxplots of the ratio of Hsp90 $\beta$ 's unique peptides MS intensity in gel band A relative to initial intensity in gel band A with $0 \mathrm{ng} / \mu \mathrm{L}$ trypsin. $p$-values comparing WT and AA samples are given above the boxes. Points represent single peptides. (D) The major tryptic cleavage site in Hsp90ß's C domain, near K607 and the major resulting products are shown. (E) Boxplots of the ratio of Hsp90 $\beta^{\prime}$ s unique peptides MS intensity in band A relative to the summed MS intensity in the rest of the lane (whole lanes were analyzed).

The ratios of the peptides before K607 are significantly lower than those after K607 when trypsin is added. The peptides after K607 are thus less abundant in the rest of the lane compared to peptides before K607, most likely because these are part of a cleavage product smaller than $40 \mathrm{kDa}$. Taken together, the data implies that S226 and S255 mutation to alanine facilitates tryptic cleavage in the C domain and suggests that S226 and S255 phosphorylation could have the opposite effect. Since the CL region is far from K607, the differences in trypsin sensitivity are presumably caused by a change in global conformation and not by a direct inhibition of trypsin by the phosphate groups.

In conclusion, limited proteolysis suggests that suppression of constitutive phosphorylation sites results in an Hsp90 $\beta$ dimer that has either a permanently more open conformation or increased structural dynamics, granting trypsin easier access to cleavage sites. Conversely, the structure of the WT, predominantly phosphorylated protein could be somewhat constrained by the modification on S226, S255.

\subsection{Both Cytosolic and Nuclear Hsp90ß Are Highly Phosphorylated on CL}

We next explored if nuclear Hsp90 $\beta$ had a different phosphorylation occupancy at S226 and S255, but occupancy in the nuclear and cytosolic fraction are in the same range (Table S2, sheet "NuclearOccupancy-K562Cells"). 


\subsection{Extracellular Hsp90ß Shows Lower Phosphosite Occupancy}

Both cytosolic Hsp90 isoforms are secreted to the extracellular space where they carry out different functions related e.g., to extracellular matrix remodeling or wound healing [97-101]. We purified extracellular Hsp90 $(\mathrm{eHsp} 90 \beta)$ from the conditioned medium (CM) of untreated K562 cells, grown in 10\% FBS, harvested at half-maximum density. We used isotopically labeled K562 cells to distinguish K562-secreted Hsp90 from bovine Hsp90 in the serum. The results are presented in Table 3 and in Table S2 sheet "ExtracellularHsp90Occupancy-K562Cells".

Table 3. Average occupancy and standard deviation (s.d.) determined for Hsp90ß immunopurified from conditioned medium of K562 suspension cultures $(n=3)$. $p$-values from a $t$-test comparing the present occupancy values with K562 intracellular Hsp90 $\beta$ occupancy values.

\begin{tabular}{ccc}
\hline Peptide & Average Occupancy \pm s.d. & Adjusted $\boldsymbol{p}$-Value \\
\hline EKEIpSDDEAEEEK & $93.3 \% \pm 0.8$ & 0.01 \\
EIpSDDEAEEEK & $94.5 \% \pm 0.4$ & $\mathrm{NA}$ \\
IEDVGpSDEEDDSGK & $85.0 \% \pm 2.2$ & 0.01 \\
IEDVGpSDEEDDSGKDKK & $81.3 \% \pm 2.8$ & 0.01 \\
\hline
\end{tabular}

Occupancy of S255 was 10\% lower in the CM than in the cell. The difference was smaller for S226, between 2 to 3\%. The occupancy is similarly high for both sites in intracellular Hsp90ß in K562 cells (Figure 1E), but there may be a difference in eHsp90ß.

\subsection{Non-Phosphorylatable Hsp90 $\beta$ Is Found in Higher Amounts in Conditioned Medium}

Next, we tested if S226 and S255 phosphorylation has an impact on Hsp90ß secretion. We transfected cells with WT or AA HA-Hsp90 $\beta$ or no plasmid as negative control, and used CWB analysis to quantify HA-tagged proteins in the cells and in the CM. $\beta$-actin was used as a non-secretory protein control (Figure 4).

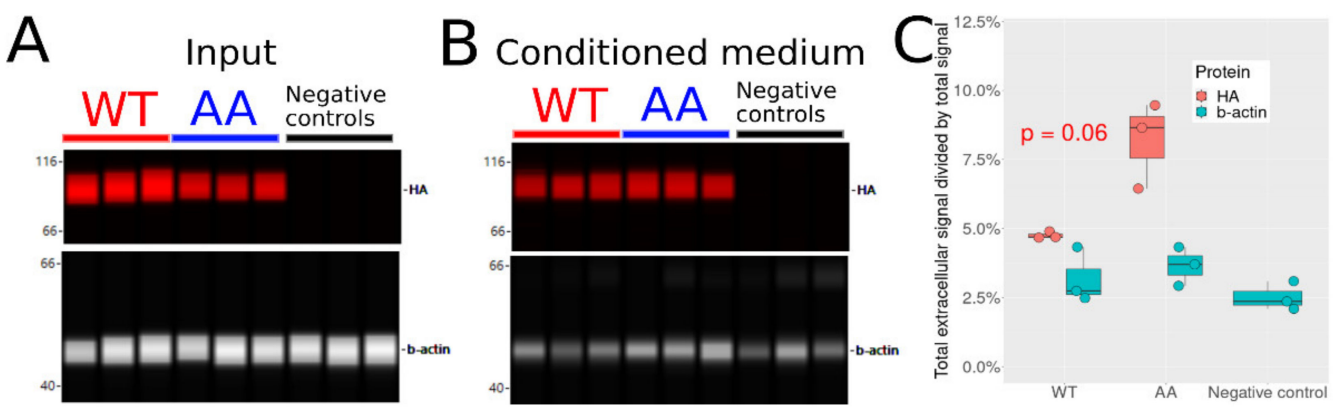

Figure 4. Levels of WT vs. AA in the CM of transfected HEK293T-Hsp90ßKO19 cells. (A) CWB detection of HA-tag (red bands) and $\beta$-actin (grey bands) in transfected HEK293T-Hsp90ßKO19 cells. Dual detection was performed on the same capillaries by chemiluminescence ( $\beta$-actin) or fluorescence (HA-tag). (B) CWB analysis of HA-tag and $\beta$-actin in CM. (C) Total absolute CWB signal in $\mathrm{CM}$ divided by total absolute CWB signal (CM plus input). Total absolute signal was adjusted to account for the totality of the sample (it is the expected signal if the whole sample was analyzed at once). Points represent replicates. In red, the $p$-value from WT vs. AA $t$-test comparison of HA signal corrected by basal $\beta$-actin release.

We found lower levels of intracellular AA compared to WT when comparing equal total protein amounts (Figure $4 \mathrm{~A}$ ). In contrast, $\mathrm{AA}$ was more abundant in the $\mathrm{CM}$ compared to WT (Figure 4B). Absolute ratios (fraction of Hsp90 $\beta$ in CM compared to total amount of Hsp90 $\beta$ in the CM and in cells) were estimated for HA-Hsp90 $\beta$ and $\beta$-actin and are shown in Figure 4C. The ratios for HA are higher than for $\beta$-actin, consistent with regulated Hsp90 $\beta$ secretion. Furthermore, the ratios are higher for AA than for WT, indicating that more AA is found in the CM than WT. It is unknown if there is a secretion capacity limit 
for Hsp90 $\beta$, but even in the situation that the limit exists and is reached, we would expect similar amounts of WT and AA in the CM since cells were transfected at the same density.

The ratio of $\beta$-actin was used to quantify the baseline of accidental protein release in the $\mathrm{CM}$, which averages at $3 \%$. By subtracting the $\beta$-actin absolute ratio to the HA absolute ratios, we estimated the fraction of secreted Hsp90 $\beta$ at $1.6 \% \pm 0.9$ for WT and $4.5 \% \pm 1.6$ for AA ( $p$-value $=0.06$, see Table S9), suggesting that AA is secreted 2 to 3 times more efficiently than WT.

In conclusion, within the cell there is no obvious difference in CL phosphosite occupancy for cytosolic vs. nuclear/organellar Hsp90 $\beta$. On the other hand, eHsp90 $\beta$ appears to be somewhat less phosphorylated than the intracellular protein. The transfected AA mutant is more efficiently secreted than the WT protein, suggesting the possibility of a causal relationship between a lower CL phosphorylation and secretion.

\section{Discussion}

Lees-Miller et al. first reported on phosphorylation of Hsp90 on the charged linker, measuring 1.7 moles of phosphate per mole of Hsp90 in HeLa cells, and identified the phosphorylated residues as S231 and S263 in Hsp90 $\alpha$, and S226 and S255 in Hsp90ß [32]. They did not detect phosphorylation on S252 in Hsp90 $\alpha$, nor on S261 in Hsp90ß. Our own results, obtained with a method targeting the residues of interest, indicate an occupancy of S226 and S255 close to 95\%, which translates into 1.9 moles phosphate per mole of Hsp90, in line with Lees-Miller et al.'s results and also with results from large scale phosphoproteomics data [102].

However, other reports showed different trends. Two studies reported reduced phosphorylation of Hsp90 $\beta$ in cells expressing leukemogenic tyrosine kinases [39,41]. Kurokawa et al. showed that Hsp90 $\beta$ was not phosphorylated on S226 and S255 when incubated in lysates of Ba/F3 cells expressing Bcr-Abl. Kim et al. reported that S226 and S255 are not modified in LS174T cells but that their phosphorylation is induced by rifampin [45]. On our side, we repeatedly measured S226, S255 phosphorylation in K562 cells, which express active Bcr-Abl, and consistently found high occupancy, contrasting Kurokawa et al.'s conclusions. Furthermore, our measurements after stress treatments suggest that phosphorylation occupancy on S226 and S255 remains high and stable in a variety of conditions that impact Hsp90 function. While our data supports the view that phosphorylation at these sites is constitutive and not regulated, the discrepancies with the aforementioned reports call for consideration of alternative interpretations and/or a more subtle model. In particular, measurement of ${ }^{32} \mathrm{P}$ incorporation (as used by Kurokawa et al.) can reflect phosphorylation turnover rather than total occupancy (that we determine with our technique). Changes in phosphorylation turnover have already been reported for Hsp90 after heat stress and would not be incompatible with a high occupancy [42] Therefore, measurements of phosphorylation turnover for the CL phosphosites could be used to shed light on these apparent conflicts.

We next addressed the effect of CL modification on Hsp90 interactions. This has been addressed in specific cases but never by a large scale, unbiased approach, as presented here $[39,44-46]$. We show that AA was able to bind almost every interactor detected, including all Hsp70 family members, co-chaperones and clients, with greater efficiency than the phosphorylated WT protein. The only interactor with more affinity for phosphorylated WT Hsp90 $\beta$ was the co-chaperone CACYBP, which was reported to have dephosphorylating activity on Hsp90 [103]. Our results are therefore compatible with data by two studies showing that similar AA mutants have increased binding to Apaf- 1 and AhR $[39,44]$. The breadth and uniformity of the effect of the mutations suggests that S226 and S255 phosphorylation does not regulate specific interactions, but rather impacts other general properties of Hsp90ß.

Still, a higher amount of interactors does not necessarily imply a higher biological activity. We therefore addressed ATP binding and hydrolysis, which are key steps in the Hsp90 chaperone cycle. We showed that AA has a slightly higher binding affinity for ATP, 
albeit the difference was not statistically significant. Since our assay is performed in a cell lysate, a possible difference correlates with the binding of more AHSA1 (which stimulates Hsp90 ATPase activity) by the AA mutant as shown by the interactome data. Both WT and AA displayed a higher affinity for ATP than ADP, a result in agreement with one study but in conflict with others $[46,104,105]$. The difference may be due to the experimental conditions (in a cell lysate vs. with purified proteins) and the readout used.

Conformational dynamics are critical for Hsp90 $\beta$ chaperone activity. We showed that S226 and S255 mutation to alanines facilitated tryptic cleavage in the C domain and possibly in the $\mathrm{N}$ domain, suggesting that lack of CL phosphorylation could shift Hsp90 $\beta$ global conformational equilibrium towards a more open state.

Several studies proposed that Hsp90 phosphorylation, notably on the CL, is linked to client release at the end of the chaperone cycle [42,47,106-108]. While our data may suggest that non phosphorylated Hsp90 has a higher affinity for clients, phosphorylated Hsp90 still binds a lot of interactors. A study even pointed out that Hsp90 $\beta$ in Hsp90 $\beta$ AhR complexes is phosphorylated on S226 and S255, amounting to a total estimate of 1.7 mole phosphate per mole Hsp90 $\beta$, thus an occupancy in the range of WT Hsp90 $\beta$ [44]. Moreover, the CL sequence is the least conserved domain of Hsp90, and these serines have appeared in higher order organisms only, arguing a priori against their importance for Hsp90 $\beta$ core chaperone functions. There are thus reasons to question the hypothesis that CL phosphosites are coupled to the progression of the chaperone cycle.

The function of S226 and S255 phosphorylation could therefore be related to cellular or organism-related functions specific to higher eukaryotes, such as localization. Our measurements showed that nuclear-localized and cytosolic Hsp90 $\beta$ had virtually identical CL phosphorylation states.

By contrast, we found a 10\% lower phosphorylation occupancy for S255, and a 2-3\% lower occupancy for S226 in eHsp90 $\beta$. The difference may be greater in reality since eHsp90 $\beta$ can be "contaminated" by Hsp90 $\beta$ released by dead or necrotic cells. To explore a potential causal relationship between S226/S255 phosphorylation and secretion, we transfected cells with WT and AA and found clearly more AA in the CM than WT, suggesting a role for CL phosphosites in regulating Hsp90 secretion. This role could be direct or indirect, with dephosphorylation facilitating C-terminal cleavage events, that have been reported by Wang et al. as a hallmark of eHsp90 [109]. CL phosphorylation may thus be part of the chaperone code, i.e., a set of hierarchical, interconnected PTM's, that is governing Hsp90 secretion [13].

Our results on the AA mutant closely recall a previous study by Tsutsumi et al., who identified a region flanking the CL whose mutation altered Hsp90 protein protein interactions, global conformation and secretion. Specifically, alanine mutations of the conserved hydrophobic motif in $\beta$-strand $8,{ }^{213} \mathrm{IxL}^{215}$ in human $\mathrm{Hsp} 90 \beta$ and ${ }^{205} \mathrm{IxL}^{207}$ in yeast Hsp90, dramatically impair Hsp90 secretion and chaperone activity, and alter protein-protein interactions as well as sensitivity to tryptic cleavage in the $C$ domain [18]. The authors showed that the mutations destabilize $\beta$-strand 8 with repercussions on hydrophobic contacts within the $\mathrm{N}$ domain, notably with $\alpha$-helix 8 . Truncation of the CL stabilized $\beta$-strand 8 in the mutants, partially restoring Hsp90 secretion and activity.

Taking these findings together with our results, we can formulate a model in which S226 and S255 phosphorylation alters the transient interactions between the C-terminal part of the CL with residual secondary structure, $\beta$-strand 9 included, and $\beta$-strand 8 . Phosphate groups in the CL may form salt bridges with the numerous lysine residues in proximity and rigidify the $\mathrm{CL}$, while dephosphorylation may result in increased flexibility. This mechanism could regulate contacts between $\beta$-strand 8 and the surrounding secondary structures: $\alpha$-helix $8, \beta$-strand 2 and in particular $\beta$-strand 9 , as $\beta$-strands 8 and 9 are separated by the CL but do interact in the closed conformations of Hsp90, forming a $\beta$-hairpin like structure $[29,31,110,111]$. These contacts may then modulate the exposure of local protein binding sites, Hsp90 $\beta$ secretion and global conformational dynamics. In addition, high occupancy of S226 and S255 may prevent excessive destabilization 
of $\beta$-strand 8 by an over-flexible, non-phosphorylated CL. From an evolutionary point of view, the prolines in the yeast CL may have been replaced in higher organisms by phosphorylation sites that are used to modulate the CL's flexibility.

\section{Conclusions}

We provided insights on the phosphorylation occupancy of S226 and S255 in various conditions and environments and on the effects of the modifications on some key molecular properties. As it often happens with Hsp90, the answers we obtained did not provide an easily intelligible picture and several unknowns remain. Disentangling the different effects of CL phosphorylation will require further investigations at different levels. To test our structural model, it will be essential to probe, for example by hydrogen/deuterium exchange, if (de-)phosphorylation of the CL impacts the exposure of the secondary structures surrounding $\beta$-strand 8 . On the functional side, it will be crucial to determine the chaperoning activity of Hsp90 in the presence/absence of the modifications. Characterizing the CL phosphorylation turnover in various conditions may also provide valuable information to understand the function of S226 and S255 in physiological states such as under stress conditions. Finally, it will be important to test the relevance of CL phosphorylation on secretion of Hsp90 $\alpha$, that is considered the major biologically active eHsp90 species.

Supplementary Materials: The following are available online at https: / www.mdpi.com/article / 10.3390 / cells10071701/s1, Figure S1: Determination of occupancy of S231 phosphosite in human Hsp90 $\alpha$, Figure S2: Label-free quantitative exploration of the interactome of WT vs. AA mutant, Figure S3: Analysis of transfected protein expression, input cell extracts, and co-IPs in the SILAC interactome experiment, Figure S4: Graph view of capillary western blot detection of HA-tag for WT or AA Hsp90 $\beta$ for increasing trypsin concentration, Figure S5: CWB raw signal ratios in the eHsp90 secretion experiment, Table S1: Occupancy PRM Masses, Table S2: Occupancy Data, Table S3: Phosphorylation In Stressed Cells, Table S4: Interactome Label-free, Table S5: Interactome SILAC, Table S6: ATP and ADP Binding, Table S7: CWB Analysis Trypsin Sensitivity, Table S8: MS Analysis Trypsin Sensitivity, Table S9: Hsp90ß secretion.

Author Contributions: Conception and design of experiments: L.W. and M.Q.; Experiments, data analysis and statistical analysis: L.W.; Writing of the manuscript: L.W. and M.Q. Both authors have read and agreed to the published version of the manuscript.

Funding: This research was funded by the SWISS NATIONAL SCIENCE FOUNDATION, grant number 31003A_166562 to M.Q. and by internal funding by UNIVERSITY OF LAUSANNE.

Institutional Review Board Statement: Not applicable.

Informed Consent Statement: Not applicable.

Data Availability Statement: The mass spectrometry proteomics data have been deposited to the ProteomeXchange Consortium via the PRIDE partner repository with the dataset identifier PXD025873, PXD025888, 10.6019/PXD025888, PXD025878 and 10.6019/PXD025878.

Acknowledgments: We thank Didier Picard for kindly providing Hsp90 $\beta-K O$ cells. We thank Pascal Cousin and Maria Cristina Gambetta for providing reagents and advice for plasmid generation. We thank Patrice Waridel and Jachen Barblan for technical assistance. We thank Séverine Lorrain for advice and technical assistance for CWB analysis. We thank Frédéric Schütz and Florence Mehl for advice on statistical analysis.

Conflicts of Interest: The authors declare no conflict of interest. The funders had no role in the design of the study; in the collection, analyses, or interpretation of data; in the writing of the manuscript, or in the decision to publish the results.

\section{References}

1. Pearl, L.H. Review: The HSP90 molecular chaperone-an enigmatic ATPase. Biopolymers 2016, 105, 594-607. [CrossRef]

2. Prodromou, C. Mechanisms of Hsp90 regulation. Biochem. J. 2016, 473, 2439-2452. [CrossRef] [PubMed]

3. Schopf, F.H.; Biebl, M.M.; Buchner, J. The HSP90 chaperone machinery. Nat. Rev. Mol. Cell Biol. 2017, 18, 345-360. [CrossRef] 
4. Sima, S.; Richter, K. Regulation of the Hsp90 system. Biochim. Biophys. Acta Mol. Cell Res. 2018, 1865, 889-897. [CrossRef] [PubMed]

5. Johnson, J.L. Evolution and function of diverse Hsp90 homologs and cochaperone proteins. Biochim. Biophys. Acta Mol. Cell Res. 2012, 1823, 607-613. [CrossRef] [PubMed]

6. Hoter, A.; El-Sabban, M.E.; Naim, H.Y. The HSP90 family: Structure, regulation, function, and implications in health and disease. Int. J. Mol. Sci. 2018, 19, 2560. [CrossRef]

7. Sreedhar, A.S.; Kalmár, E.; Csermely, P.; Shen, Y.-F. Hsp90 isoforms: Functions, expression and clinical importance. FEBS Lett. 2004, 562, 11-15. [CrossRef]

8. Cox, M.B.; Johnson, J.L. Evidence for Hsp90 co-chaperones in regulating Hsp90 function and promoting client protein folding. Methods Mol. Biol. 2018, 1709, 397-422. [CrossRef]

9. Mollapour, M.; Neckers, L. Post-translational modifications of Hsp90 and their contributions to chaperone regulation. Biochim. Biophys. Acta 2012, 1823, 648-655. [CrossRef] [PubMed]

10. Prodromou, C. The "active life" of Hsp90 complexes. Biochim. Biophys. Acta 2012, 1823, 614-623. [CrossRef] [PubMed]

11. Sager, R.A.; Woodford, M.R.; Neckers, L.; Mollapour, M. Detecting posttranslational modifications of Hsp90. Methods Mol. Biol. 2018, 1709, 209-219. [CrossRef]

12. Dean, M.E.; Johnson, J.L. Human Hsp90 cochaperones: Perspectives on tissue-specific expression and identification of cochaperones with similar in vivo functions. Cell Stress Chaperones 2021, 26, 3-13. [CrossRef]

13. Backe, S.J.; Sager, R.A.; Woodford, M.R.; Makedon, A.M.; Mollapour, M. Post-translational modifications of Hsp90 and translating the chaperone code. J. Biol. Chem. 2020, 295, 11099-11117. [CrossRef] [PubMed]

14. Gupta, R.S. Phylogenetic analysis of the $90 \mathrm{kD}$ heat shock family of protein sequences and an examination of the relationship among animals, plants, and fungi species. Mol. Biol. Evol. 1995, 12, 1063-1073. [CrossRef] [PubMed]

15. Binart, N.; Chambraud, B.; Levin, J.M.; Garnier, J.; Baulieu, E.E. A highly charged sequence of chick hsp90: A good candidate for interaction with steroid receptors. J. Steroid Biochem. 1989, 34, 369-374. [CrossRef]

16. Tbarka, N.; Richard-Méreau, C.; Formstecher, P.; Dautrevaux, M. Biochemical and immunological evidence that an acidic domain of hsp 90 is involved in the stabilization of untransformed glucocorticoid receptor complexes. FEBS Lett. 1993, 322, 125-128. [CrossRef]

17. Hainzl, O.; Lapina, M.C.; Buchner, J.; Richter, K. The charged linker region is an important regulator of Hsp90 function. J. Biol. Chem. 2009, 284, 22559-22567. [CrossRef]

18. Tsutsumi, S.; Mollapour, M.; Graf, C.; Lee, C.-T.; Scroggins, B.T.; Xu, W.; Haslerova, L.; Hessling, M.; Konstantinova, A.A.; Trepel, J.B.; et al. Hsp90 charged-linker truncation reverses the functional consequences of weakened hydrophobic contacts in the $\mathrm{N}$ domain. Nat. Struct. Mol. Biol. 2009, 16, 1141-1147. [CrossRef]

19. Tsutsumi, S.; Mollapour, M.; Prodromou, C.; Lee, C.-T.; Panaretou, B.; Yoshida, S.; Mayer, M.P.; Neckers, L.M. Charged linker sequence modulates eukaryotic heat shock protein 90 (Hsp90) chaperone activity. Proc. Natl. Acad. Sci. USA 2012, 109, $2937-2942$. [CrossRef]

20. Jahn, M.; Rehn, A.; Pelz, B.; Hellenkamp, B.; Richter, K.; Rief, M.; Buchner, J.; Hugel, T. The charged linker of the molecular chaperone Hsp90 modulates domain contacts and biological function. Proc. Natl. Acad. Sci. USA 2014, 111, 17881-17886. [CrossRef]

21. Suhane, T.; Laskar, S.; Advani, S.; Roy, N.; Varunan, S.; Bhattacharyya, D.; Bhattacharyya, S.; Bhattacharyya, M.K. Both the charged linker region and ATPase domain of Hsp90 are essential for Rad51-dependent DNA repair. Eukaryot. Cell 2015, 14, 64-77. [CrossRef] [PubMed]

22. Daturpalli, S.; Knieß, R.A.; Lee, C.-T.; Mayer, M.P. Large Rotation of the N-terminal domain of Hsp90 is important for interaction with some but not all client proteins. J. Mol. Biol. 2017, 429, 1406-1423. [CrossRef] [PubMed]

23. Cadepond, F.; Jibard, N.; Binart, N.; Schweizer-Groyer, G.; Segard-Maurel, I.; Baulieu, E.E. Selective deletions in the 90 kDa heat shock protein (hsp90) impede hetero-oligomeric complex formation with the glucocorticosteroid receptor (GR) or hormone binding by GR. J. Steroid Biochem. Mol. Biol. 1994, 48, 361-367. [CrossRef]

24. Binart, N.; Lombès, M.; Baulieu, E.E. Distinct functions of the $90 \mathrm{kDa}$ heat-shock protein (hsp90) in oestrogen and mineralocorticosteroid receptor activity: Effects of hsp90 deletion mutants. Biochem. J. 1995, 311 Pt 3, 797-804. [CrossRef]

25. Dao-Phan, H.P.; Formstecher, P.; Lefebvre, P. Disruption of the glucocorticoid receptor assembly with heat shock protein 90 by a peptidic antiglucocorticoid. Mol. Endocrinol. 1997, 11, 962-972. [CrossRef]

26. Scheibel, T.; Siegmund, H.I.; Jaenicke, R.; Ganz, P.; Lilie, H.; Buchner, J. The charged region of Hsp90 modulates the function of the N-terminal domain. Proc. Natl. Acad. Sci. USA 1999, 96, 1297-1302. [CrossRef]

27. Louvion, J.F.; Warth, R.; Picard, D. Two eukaryote-specific regions of Hsp82 are dispensable for its viability and signal transduction functions in yeast. Proc. Natl. Acad. Sci. USA 1996, 93, 13937-13942. [CrossRef]

28. Meng, X.; Devin, J.; Sullivan, W.P.; Toft, D.; Baulieu, E.E.; Catelli, M.G. Mutational analysis of Hsp90 alpha dimerization and subcellular localization: Dimer disruption does not impede "in vivo" interaction with estrogen receptor. J. Cell Sci. 1996, 109 Pt 7 , 1677-1687. [CrossRef]

29. Huai, Q.; Wang, H.; Liu, Y.; Kim, H.Y.; Toft, D.; Ke, H. Structures of the N-terminal and middle domains of E. coli Hsp90 and conformation changes upon ADP binding. Structure 2005, 13, 579-590. [CrossRef] 
30. Binart, N.; Chambraud, B.; Dumas, B.; Rowlands, D.A.; Bigogne, C.; Levin, J.M.; Garnier, J.; Baulieu, E.E.; Catelli, M.G. The cDNA-derived amino acid sequence of chick heat shock protein Mr 90,000 (HSP 90) reveals a "DNA like" structure: Potential site of interaction with steroid receptors. Biochem. Biophys. Res. Commun. 1989, 159, 140-147. [CrossRef]

31. López, A.; Elimelech, A.R.; Klimm, K.; Sattler, M. The charged linker modulates conformations and molecular interactions of Hsp90. ChemBioChem 2020. [CrossRef]

32. Lees-Miller, S.P.; Anderson, C.W. Two human 90-kDa heat shock proteins are phosphorylated in vivo at conserved serines that are phosphorylated in vitro by casein kinase II. J. Biol. Chem. 1989, 264, 2431-2437. [CrossRef]

33. Kelley, P.M.; Schlesinger, M.J. Antibodies to two major chicken heat shock proteins cross-react with similar proteins in widely divergent species. Mol. Cell. Biol. 1982, 2, 267-274. [CrossRef]

34. Iannotti, A.M.; Rabideau, D.A.; Dougherty, J.J. Characterization of purified avian 90,000-Da heat shock protein. Arch. Biochem. Biophys. 1988, 264, 54-60. [CrossRef]

35. Lundby, A.; Secher, A.; Lage, K.; Nordsborg, N.B.; Dmytriyev, A.; Lundby, C.; Olsen, J. V Quantitative maps of protein phosphorylation sites across 14 different rat organs and tissues. Nat. Commun. 2012, 3, 876. [CrossRef] [PubMed]

36. Garnier, C.; Lafitte, D.; Jorgensen, T.J.D.; Jensen, O.N.; Briand, C.; Peyrot, V. Phosphorylation and oligomerization states of native pig brain HSP90 studied by mass spectrometry. Eur. J. Biochem. 2001, 268, 2402-2407. [CrossRef] [PubMed]

37. Franchin, C.; Cesaro, L.; Salvi, M.; Millioni, R.; Iori, E.; Cifani, P.; James, P.; Arrigoni, G.; Pinna, L. Quantitative analysis of a phosphoproteome readily altered by the protein kinase CK2 inhibitor quinalizarin in HEK-293T cells. Biochim. Biophys. Acta 2015, 1854, 609-623. [CrossRef] [PubMed]

38. Franchin, C.; Borgo, C.; Cesaro, L.; Zaramella, S.; Vilardell, J.; Salvi, M.; Arrigoni, G.; Pinna, L.A. Re-evaluation of protein kinase CK2 pleiotropy: New insights provided by a phosphoproteomics analysis of CK2 knockout cells. Cell. Mol. Life Sci. 2018, 75, 2011-2026. [CrossRef]

39. Kurokawa, M.; Zhao, C.; Reya, T.; Kornbluth, S. Inhibition of apoptosome formation by suppression of Hsp90beta phosphorylation in tyrosine kinase-induced leukemias. Mol. Cell. Biol. 2008, 28, 5494-5506. [CrossRef] [PubMed]

40. Lee, C.F.; Griffiths, S.; Rodríguez-Suárez, E.; Pierce, A.; Unwin, R.D.; Jaworska, E.; Evans, C.A.; Gaskell, S.J.; Whetton, A.D. Assessment of downstream effectors of BCR/ABL protein tyrosine kinase using combined proteomic approaches. Proteomics 2010, 10, 3321-3342. [CrossRef] [PubMed]

41. Unwin, R.D.; Sternberg, D.W.; Lu, Y.; Pierce, A.; Gilliland, D.G.; Whetton, A.D. Global effects of BCR/ABL and TEL/PDGFRbeta expression on the proteome and phosphoproteome: Identification of the Rho pathway as a target of BCR/ABL. J. Biol. Chem. 2005, 280, 6316-6326. [CrossRef]

42. Legagneux, V.; Morange, M.; Bensaude, O. Heat shock increases turnover of $90 \mathrm{kDa}$ heat shock protein phosphate groups in HeLa cells. FEBS Lett. 1991, 291, 359-362. [CrossRef]

43. Weeraphan, C.; Phongdara, A.; Chaiyawat, P.; Diskul-Na-Ayudthaya, P.; Chokchaichamnankit, D.; Verathamjamras, C.; Netsirisawan, P.; Yingchutrakul, Y.; Roytrakul, S.; Champattanachai, V.; et al. Phosphoproteome Profiling of isogenic cancer cell-derived exosome reveals HSP90 as a potential marker for human cholangiocarcinoma. Proteomics 2019, 19, e1800159. [CrossRef]

44. Ogiso, H.; Kagi, N.; Matsumoto, E.; Nishimoto, M.; Arai, R.; Shirouzu, M.; Mimura, J.; Fujii-Kuriyama, Y.; Yokoyama, S. Phosphorylation analysis of $90 \mathrm{kDa}$ heat shock protein within the cytosolic arylhydrocarbon receptor complex. Biochemistry 2004, 43, 15510-15519. [CrossRef]

45. Kim, S.W.; Hasanuzzaman, M.; Cho, M.; Heo, Y.R.; Ryu, M.-J.; Ha, N.-Y.; Park, H.J.; Park, H.-Y.; Shin, J.-G. Casein Kinase 2 (CK2)-mediated Phosphorylation of Hsp90ß as a Novel Mechanism of Rifampin-induced MDR1 Expression. J. Biol. Chem. 2015, 290, 17029-17040. [CrossRef] [PubMed]

46. Olesen, S.H.; Ingles, D.J.; Zhu, J.Y.; Martin, M.P.; Betzi, S.; Georg, G.I.; Tash, J.S.; Schönbrunn, E. Stability of the human Hsp90p50Cdc37 chaperone complex against nucleotides and Hsp90 inhibitors, and the influence of phosphorylation by casein kinase 2. Molecules 2015, 20, 1643-1660. [CrossRef]

47. Woo, S.H.; An, S.; Lee, H.-C.; Jin, H.-O.; Seo, S.-K.; Yoo, D.-H.; Lee, K.-H.; Rhee, C.H.; Choi, E.-J.; Hong, S.-I.; et al. A truncated form of p23 down-regulates telomerase activity via disruption of Hsp90 function. J. Biol. Chem. 2009, 284, 30871-30880. [CrossRef]

48. Bhattacharya, K.; Weidenauer, L.; Luengo, T.M.; Pieters, E.C.; Echeverría, P.C.; Bernasconi, L.; Wider, D.; Sadian, Y.; Koopman, M.B.; Villemin, M.; et al. The Hsp70-Hsp90 co-chaperone Hop/Stip1 shifts the proteostatic balance from folding towards degradation. Nat. Commun. 2020, 11, 5975. [CrossRef]

49. Ong, S.E.; Blagoev, B.; Kratchmarova, I.; Kristensen, D.B.; Steen, H.; Pandey, A.; Mann, M. Stable isotope labeling by amino acids in cell culture, SILAC, as a simple and accurate approach to expression proteomics. Mol. Cell. Proteom. 2002, 1, 376-386. [CrossRef] [PubMed]

50. Chen, C.; Okayama, H. High-efficiency transformation of mammalian cells by plasmid DNA. Mol. Cell. Biol. 1987, 7, $2745-2752$. [CrossRef] [PubMed]

51. Kulak, N.A.; Pichler, G.; Paron, I.; Nagaraj, N.; Mann, M. Minimal, encapsulated proteomic-sample processing applied to copy-number estimation in eukaryotic cells. Nat. Methods 2014, 11, 319-324. [CrossRef] [PubMed]

52. Cox, J.; Mann, M. MaxQuant enables high peptide identification rates, individualized p.p.b.-range mass accuracies and proteomewide protein quantification. Nat. Biotechnol. 2008, 26, 1367-1372. [CrossRef] [PubMed]

53. Cox, J.; Neuhauser, N.; Michalski, A.; Scheltema, R.A.; Olsen, J.V.; Mann, M. Andromeda: A peptide search engine integrated into the MaxQuant environment. J. Proteome Res. 2011, 10, 1794-1805. [CrossRef] 
54. Cox, J.; Hein, M.Y.; Luber, C.A.; Paron, I.; Nagaraj, N.; Mann, M. Accurate proteome-wide label-free quantification by delayed normalization and maximal peptide ratio extraction, termed MaxLFQ. Mol. Cell. Proteom. 2014, 13, 2513-2526. [CrossRef]

55. R Core Team. R: A Language and Environment for Statistical Computing; R Foundation for Statistical Computing: Vienna, Austria, 2020; Available online: https:/ / www.R-project.org/ (accessed on 17 May 2021).

56. Wickham, H. The split-apply-combine strategy for data analysis. J. Stat. Softw. 2011, 40, 1-29. [CrossRef]

57. Sievert, C. Interactive Web-Based Data Visualization with R, Plotly, and Shiny; Chapman and Hall/CRC: Boca Raton, FL, USA, 2020; ISBN 9781138331457.

58. Thevenot, E.A. Ropls: PCA, PLS(-DA) and OPLS(-DA) for Multivariate Analysis and Feature Selection of Omics Data. R package version 1.20.0. 2020. Available online: https://bioconductor.statistik.tu-dortmund.de/packages/3.6/bioc/vignettes/ropls/inst/ doc/ropls-vignette.pdf (accessed on 17 May 2021).

59. Yu, G.; Wang, L.-G.; Han, Y.; He, Q.-Y. clusterProfiler: An R package for comparing biological themes among gene clusters. Omics A J. Integr. Biol. 2012, 16, 284-287. [CrossRef]

60. Thévenot, E.A.; Roux, A.; Xu, Y.; Ezan, E.; Junot, C. Analysis of the human adult urinary metabolome variations with age, body mass index, and gender by implementing a comprehensive workflow for univariate and OPLS statistical analyses. J. Proteome Res. 2015, 14, 3322-3335. [CrossRef]

61. Xie, Y.; Allaire, J.J.; Grolemund, G. R Markdown: The Definitive Guide; Chapman and Hall/CRC: Boca Raton, FL, USA, 2018.

62. Xie, Y. TinyTeX: A lightweight, cross-platform, and easy-to-maintain LaTeX distribution based on TeX Live. TUGboat 2019, 40, 30-32.

63. Wickham, H.; Chang, W.; Henry, L.; Pedersen, T.L.; Takahashi, K.; Wilke, C.; Woo, K.; Yutani, H.; Dunnington, D. ggplot2; Springer: New York, NY, USA, 2016; ISBN 978-3-319-24277-4.

64. Xie, Y. knitr: A General-Purpose Package for Dynamic Report Generation in R; R package version 1.29. 2020. Available online: https: / /CRAN.R-project.org/package=knitr (accessed on 17 May 2021).

65. Allaire, J.J.; Xie, Y.; McPherson, J.; Luraschi, J.; Ushey, K.; Atkins, A.; Wickham, H.; Cheng, J.; Chang, W.; Iannone, R. Rmarkdown: Dynamic Documents for R. R package version 2.3; R-Studio: Boston, MA, USA, 2020. Available online: https://rmarkdown.rstudio. com (accessed on 17 May 2021).

66. Pagès, H.; Carlson, M.; Falcon, S.; Li, N. AnnotationDbi: Manipulation of SQLite-Based Annotations in Bioconductor. R package version 1.50.3. 2020. Available online: https://bioconductor.org/packages/release/bioc/html/AnnotationDbi.html (accessed on 17 May 2021).

67. Auguie, B. gridExtra: Miscellaneous Functions for "Grid" Graphics, R package version 2.3. 2017. Available online: https: / /CRAN.R-project.org/package=gridExtra (accessed on 17 May 2021).

68. Oehlschlägel, J.; Ripley, B. bit: Classes and Methods for Fast Memory-Efficient Boolean Selections; R package version 4.0.4. 2020. Available online: https: / /CRAN.R-project.org/package=bit (accessed on 17 May 2021).

69. Yu, G. DOSE: Disease Ontology Semantic and Enrichment Analysis. R package version 3.14.0. 2020. Available online: https: //guangchuangyu.github.io/software/DOSE (accessed on 17 May 2021).

70. Yu, G.; Wang, L.-G.; Yan, G.-R.; He, Q.-Y. DOSE: An R/Bioconductor package for disease ontology semantic and enrichment analysis. Bioinformatics 2015, 31, 608-609. [CrossRef]

71. Yu, G. ReactomePA: Reactome Pathway Analysis. R package version 1.32.0. 2020. Available online: https://guangchuangyu. github.io/software/ReactomePA (accessed on 17 May 2021).

72. Inkscape Project. Inkscape: Open Source Scalable Vector Graphics Editor. Version 0.92.5. 2020. Available online: https: //inkscape.org/ (accessed on 17 May 2021).

73. Yu, G.; He, Q.-Y. ReactomePA: An R/Bioconductor package for reactome pathway analysis and visualization. Mol. Biosyst. 2016, 12, 477-479. [CrossRef]

74. Li, J. DO.db: A Set of Annotation Maps Describing the Entire Disease Ontology. R package version 2.9. 2015. Available online: https:/ / bioconductor.org/packages/release/data/annotation/html/DO.db.html (accessed on 17 May 2021).

75. Acker, D. gg3D: 3D Perspective Plots for ggplot2. R package version 0.0.0.9. 2020. Available online: https://github.com/ AckerDWM/gg3D (accessed on 17 May 2021).

76. Campitelli, E. ggnewscale: Multiple Fill and Colour Scales in "ggplot2". R package version 0.4.5. 2021. Available online: https: / /CRAN.R-project.org/package=ggnewscale (accessed on 17 May 2021).

77. Zhu, H. kableExtra: Construct Complex Table with "kable" and Pipe Syntax. R package version 1.1.0. 2019. Available online: https: / /CRAN.R-project.org/package=kableExtra (accessed on 17 May 2021).

78. Kassambara, A. ggpubr: "ggplot2" Based Publication Ready Plots. R package version 0.4.0. 2020. Available online: https: / /CRAN.R-project.org/package=ggpubr (accessed on 17 May 2021).

79. Pedersen, T.L. ggraph: An Implementation of Grammar of Graphics for Graphs and Networks. R package version 2.0.3. 2020. Available online: https: / /CRAN.R-project.org/package=ggraph (accessed on 17 May 2021).

80. Wickham, H. stringr: Simple, Consistent Wrappers for Common String Operations. R package version 1.4.0. 2019. Available online: https: / /CRAN.R-project.org/package=stringr (accessed on 17 May 2021).

81. Bache, S.M.; Wickham, H. magrittr: A Forward-Pipe Operator for R. R package version 1.5. 2014. Available online: https: / /CRAN.R-project.org/package=magrittr (accessed on 17 May 2021). 
82. Carlson, M. org.Hs.eg.db: Genome wide annotation for Human. R package version 3.11.14. 2020. Available online: https: // bioconductor.org/packages/release/data/annotation/html/org.Hs.eg.db.html (accessed on 17 May 2021).

83. Luo; Weijun; Brouwer; Cory Pathview: An R/Bioconductor package for pathway-based data integration and visualization. Bioinformatics 2013, 29, 1830-1831. [CrossRef]

84. Luo, W. Pathview: A Tool Set for Pathway Based Data Integration and Visualization. R package version 1.28.1. 2020. Available online: https: / / pathview.uncc.edu (accessed on 17 May 2021).

85. Sievert, C.; Parmer, C.; Hocking, T.; Chamberlain, S.; Ram, K.; Corvellec, M.; Despouy, P. plotly: Create Interactive Web Graphics via "plotly.js". R package version 4.9.2.1. 2020. Available online: https:/ /CRAN.R-project.org/package=plotly (accessed on 17 May 2021).

86. Perkins, D.N.; Pappin, D.J.; Creasy, D.M.; Cottrell, J.S. Probability-based protein identification by searching sequence databases using mass spectrometry data. Electrophoresis 1999, 20, 3551-3567. [CrossRef]

87. Pino, L.K.; Searle, B.C.; Bollinger, J.G.; Nunn, B.; MacLean, B.; MacCoss, M.J. The Skyline ecosystem: Informatics for quantitative mass spectrometry proteomics. Mass Spectrom. Rev. 2020, 39, 229-244. [CrossRef]

88. Schilling, B.; Rardin, M.J.; MacLean, B.X.; Zawadzka, A.M.; Frewen, B.E.; Cusack, M.P.; Sorensen, D.J.; Bereman, M.S.; Jing, E.; $\mathrm{Wu}$, C.C.; et al. Platform-independent and label-free quantitation of proteomic data using MS1 extracted ion chromatograms in skyline: Application to protein acetylation and phosphorylation. Mol. Cell. Proteom. 2012, 11, 202-214. [CrossRef] [PubMed]

89. Olsen, J.V.; Vermeulen, M.; Santamaria, A.; Kumar, C.; Miller, M.L.; Jensen, L.J.; Gnad, F.; Cox, J.; Jensen, T.S.; Nigg, E.A.; et al. Quantitative phosphoproteomics reveals widespread full phosphorylation site occupancy during mitosis. Sci. Signal. 2010, 3, ra3. [CrossRef]

90. Shevchenko, A.; Tomas, H.; Havliš, J.; Olsen, J.V.; Mann, M. In-gel digestion for mass spectrometric characterization of proteins and proteomes. Nat. Protoc. 2007, 1, 2856-2860. [CrossRef] [PubMed]

91. Cortes, S.; Baker-Williams, A.J.; Mollapour, M.; Bourboulia, D. Detection and Analysis of Extracellular Hsp90 (eHsp90). In Rules of Thumb for Chemical Engineers; Elsevier: Amsterdam, The Netherlands, 2018; Volume 1709, pp. 321-329.

92. Perez-Riverol, Y.; Csordas, A.; Bai, J.; Bernal-Llinares, M.; Hewapathirana, S.; Kundu, D.J.; Inuganti, A.; Griss, J.; Mayer, G.; Eisenacher, M.; et al. The PRIDE database and related tools and resources in 2019: Improving support for quantification data. Nucleic Acids Res. 2019, 47, D442-D450. [CrossRef]

93. Deutsch, E.W.; Bandeira, N.; Sharma, V.; Perez-Riverol, Y.; Carver, J.J.; Kundu, D.J.; García-Seisdedos, D.; Jarnuczak, A.F.; Hewapathirana, S.; Pullman, B.S.; et al. The ProteomeXchange consortium in 2020: Enabling "big data" approaches in proteomics. Nucleic Acids Res. 2020, 48, D1145-D1152. [CrossRef]

94. Šlechtová, T.; Gilar, M.; Kalíková, K.; Tesařová, E. Insight into trypsin miscleavage: Comparison of kinetic constants of problematic peptide sequences. Anal. Chem. 2015, 87, 7636-7643. [CrossRef]

95. Nordin, B.E.; Liu, Y.; Aban, A.; Brown, H.E.; Wu, J.; Hainley, A.K.; Rosenblum, J.S.; Nomanbhoy, T.K.; Kozarich, J.W. ATP acyl phosphate reactivity reveals native conformations of Hsp90 paralogs and inhibitor target engagement. Biochemistry 2015, 54, 3024-3036. [CrossRef]

96. Beebe, K.; Mollapour, M.; Scroggins, B.; Prodromou, C.; Xu, W.; Tokita, M.; Taldone, T.; Pullen, L.; Zierer, B.K.; Lee, J.; et al. Post-translational modification and conformational state of Heat Shock Protein 90 differentially affect binding of chemically diverse small molecule inhibitors. Oncotarget 2013, 4, 1065-1074. [CrossRef] [PubMed]

97. Guo, J.; Chang, C.; Li, W. The role of secreted heat shock protein-90 (Hsp90) in wound healing-how could it shape future therapeutics? Expert Rev. Proteom. 2017, 14. [CrossRef]

98. Wong, D.S.; Jay, D.G. Emerging roles of extracellular Hsp90 in cancer. Adv. Cancer Res. 2016, 129, 141-163. [CrossRef]

99. Tsutsumi, S.; Neckers, L. Extracellular heat shock protein 90: A role for a molecular chaperone in cell motility and cancer metastasis. Cancer Sci. 2007, 98, 1536-1539. [CrossRef]

100. Li, W.; Sahu, D.; Tsen, F. Secreted heat shock protein-90 (Hsp90) in wound healing and cancer. Biochim. Biophys. Acta Mol. Cell Res. 2012, 1823, 730-741. [CrossRef] [PubMed]

101. Cheng, C.F.; Sahu, D.; Tsen, F.; Zhao, Z.; Fan, J.; Kim, R.; Wang, X.; O’Brien, K.; Li, Y.; Kuang, Y.; et al. A fragment of secreted Hsp90 $\alpha$ carries properties that enable it to accelerate effectively both acute and diabetic wound healing in mice. J. Clin. Investig. 2011, 121, 4348-4361. [CrossRef] [PubMed]

102. Tsai, C.; Wang, Y.; Yen, H.; Tsou, C.; Ku, W.; Lin, P.; Chen, H.-Y.; Nesvizhskii, A.I.; Ishihama, Y.; Chen, Y. Large-scale determination of absolute phosphorylation stoichiometries in human cells by motif-targeting quantitative proteomics. Nat. Commun. 2015, 6 , 6622. [CrossRef] [PubMed]

103. Góral, A.; Bieganowski, P.; Prus, W.; Krzemieñ-Ojak, Ł.; Dziołka, B.K.; Fabczak, H.; Filipek, A. Calcyclin binding protein/siah-1 interacting protein is a hsp90 binding chaperone. PLoS ONE 2016, 11, 1-18. [CrossRef]

104. Prodromou, C.; Roe, S.M.; O’Brien, R.; Ladbury, J.E.; Piper, P.W.; Pearl, L.H. Identification and structural characterization of the ATP/ADP-binding site in the Hsp90 molecular chaperone. Cell 1997, 90, 65-75. [CrossRef]

105. McLaughlin, S.H.; Ventouras, L.-A.; Lobbezoo, B.; Jackson, S.E. Independent ATPase activity of Hsp90 subunits creates a flexible assembly platform. J. Mol. Biol. 2004, 344, 813-826. [CrossRef]

106. Mimnaugh, E.G.; Worland, P.J.; Whitesell, L.; Neckers, L.M. Possible role for serine/threonine phosphorylation in the regulation of the heteroprotein complex between the hsp90 stress protein and the pp60v-src tyrosine kinase. J. Biol. Chem. 1995, 270, 28654-28659. [CrossRef] [PubMed] 
107. Zhao, Y.G.; Gilmore, R.; Leone, G.; Coffey, M.C.; Weber, B.; Lee, P.W.K. Hsp90 phosphorylation is linked to its chaperoning function: Assembly of the reovirus cell attachment protein. J. Biol. Chem. 2001, 276, 32822-32827. [CrossRef] [PubMed]

108. Csermely, P.; Kahn, C.R. The 90-kDa heat shock protein (hsp-90) possesses an ATP binding site and autophosphorylating activity. J. Biol. Chem. 1991, 266, 4943-4950. [CrossRef]

109. Wang, X.; Song, X.; Zhuo, W.; Fu, Y.; Shi, H.; Liang, Y.; Tong, M.; Chang, G.; Luo, Y. The regulatory mechanism of Hsp90alpha secretion and its function in tumor malignancy. Proc. Natl. Acad. Sci. USA 2009, 106, 21288-21293. [CrossRef]

110. Ali, M.M.U.; Roe, S.M.; Vaughan, C.K.; Meyer, P.; Panaretou, B.; Piper, P.W.; Prodromou, C.; Pearl, L.H. Crystal structure of an Hsp90-nucleotide-p23/Sba1 closed chaperone complex. Nature 2006, 440, 1013-1017. [CrossRef]

111. Verba, K.A.; Wang, R.Y.-R.; Arakawa, A.; Liu, Y.; Shirouzu, M.; Yokoyama, S.; Agard, D.A. Atomic structure of Hsp90-Cdc37-Cdk4 reveals that Hsp90 traps and stabilizes an unfolded kinase. Science 2016, 352, 1542-1547. [CrossRef] [PubMed] 